\title{
Cx43-hemichannel function and regulation in physiology and pathophysiology: insights from the bovine corneal endothelial cell system and beyond
}

\section{Catheleyne D'hondt ${ }^{1}$, Jegan lyyathurai ${ }^{1}$, Bernard Himpens ${ }^{1}$, Luc Leybaert ${ }^{2}$ and Geert Bultynck ${ }^{1 *}$}

${ }^{1}$ Laboratory of Molecular and Cellular Signaling, Department of Cellular and Molecular Medicine, Katholieke Universiteit Leuven, Leuven, Belgium

2 Physiology Group, Department of Basic Medical Sciences, Faculty of Medicine and Health Sciences, Ghent University, Ghent, Belgium

Edited by:

Mauricio Antonio Retamal,

Universidad del Desarrollo, Chile

Reviewed by:

Martin Diener, University Giessen,

Germany

Aida Salameh, Heart Centre

University of Leipzig, Germany

Juan Andrés Orellana, Pontificia

Universidad Católica de Chile, Chile

*Correspondence:

Catheleyne D'hondt and Geert

Bultynck, Laboratory of Molecular

and Cellular Signaling, Department

of Cellular and Molecular Medicine

KU Leuven, Campus Gasthuisberg

$\mathrm{O} / \mathrm{N}-1$ bus 802 , Herestraat 49 ,

BE-3000 Leuven, Belgium

e-mail: catheleyne.dhondt@

med.kuleuven.be;

geert.bultynck@med.kuleuven.be
Intercellular communication in primary bovine corneal endothelial cells (BCECs) is mainly driven by the release of extracellular ATP through $\mathrm{C} \times 43$ hemichannels. Studying the characteristics of $\mathrm{Ca}^{2+}$-wave propagation in BCECs, an important form of intercellular communication, in response to physiological signaling events has led to the discovery of important insights in the functional properties and regulation of native $\mathrm{C} \times 43$ hemichannels. Together with ectopic expression models for $\mathrm{C} \times 43$ hemichannels and truncated/mutated Cx43 versions, it became very clear that loop/tail interactions play a key role in controlling the activity of $\mathrm{Cx} 43$ hemichannels. Interestingly, the negative regulation of Cx43 hemichannels by enhanced actin/myosin contractility seems to impinge upon loss of these loop/tail interactions essential for opening Cx43 hemichannels. Finally, these molecular insights have spurred the development of novel peptide tools that can selectively inhibit $\mathrm{C} \times 43$ hemichannels, but neither $\mathrm{Cx} 43$ gap junctions nor hemichannels formed by other $\mathrm{Cx}$ isoforms. These tools now set the stage to hunt for novel physiological functions for $\mathrm{C} \times 43$ hemichannels in primary cells and tissues and to tackle disease conditions associated with excessive, pathological Cx43-hemichannel openings.

Keywords: intercellular communication, hemichannels, loop/tail interactions, actin/myosin contractility, selective inhibition of Cx43 hemichannels, corneal endothelial cells

\section{PROPERTIES OF THE BOVINE CORNEA WITH FOCUS ON THE ENDOTHELIAL CELL LAYER MORPHOLOGICAL PROPERTIES}

The cornea is a transparent, convex, avascular continuation of the sclera covering the front part of the eye. Light enters the eye through the cornea, which provides about $2 / 3$ of the eye's refractive power and forms together with the lens the focusing power of the eye (Maurice, 1957). At the posterior side of the cornea lies the anterior segment, which contains aqueous humor. The delicate balance between the production and absorption of aqueous humor keeps the anterior chamber pressurized $(\sim 20 \mathrm{~mm} \mathrm{Hg})$ contributing to the maintenance of the curvature of the cornea. When this balance is disturbed glaucoma can occur (Tandon and Autar, 1989). Unlike most tissues in the body, the cornea is avascular; it contains no blood vessels to nourish it or to protect it against infection. Instead, tiny vessels at the outermost edge of the cornea along with the tears and aqueous humor take care of cell nourishment. The adult human cornea is $\sim 0.5$ millimeter thick and is arranged in five basic layers: the stratified epithelium, Bowman's membrane, stroma, Descemet's membrane and the endothelium (Figure 1A). The bovine cornea is thicker than the human cornea due to a thicker stroma and more epithelial cell layers (Figure 1B). The endothelium is the innermost layer of the cornea, located just underneath Descemet's membrane, and forms an interface between the stroma and anterior chamber. The corneal endothelium is a
4-6 $\mu \mathrm{m}$ thick, non-regenerative monolayer of polygonal-shaped, mostly hexagonal cells (Figures 1C,D) with a diameter of about $20 \mu \mathrm{m}$ (Joyce, 2003). The human corneal endothelium consists of about 400,000 cells. On the apical cell surface facing the anterior chamber, numerous small microvilli are present, and extensive interdigitations appear on lateral and basal plasma membranes. A circumferential band of actin filaments, located toward the api$\mathrm{cal}$ aspect of the cells, helps to maintain cell shape and mediates cellular migration. The corneal endothelial monolayer is able to persist thanks to the complex interplay between the extracellular matrix, integrins, interendothelial junction proteins and the actin cytoskeleton. As in vascular endothelium, corneal endothelial cells are interconnected by a complex set of interendothelial junction proteins that comprise tight junctions, adherens junctions and gap junctions. Whereas gap junctions form plaques of transmembrane channels between adjacent cells, tight junctions form a belt around the apical pole of a polar cell making a tight connection with the belt around the neighboring cells and adherens junctions form pericellular zipperlike structures along the cell border through their transmembrane homophilic adhesion (for review see Mehta and Malik, 2006).

\section{PHYSIOLOGICAL PROPERTIES}

The cornea with its smooth, transparent, strong and durable characteristics has several functions in the eye. The transparent convex surface of the cornea acts as the eye's outermost optical element of 

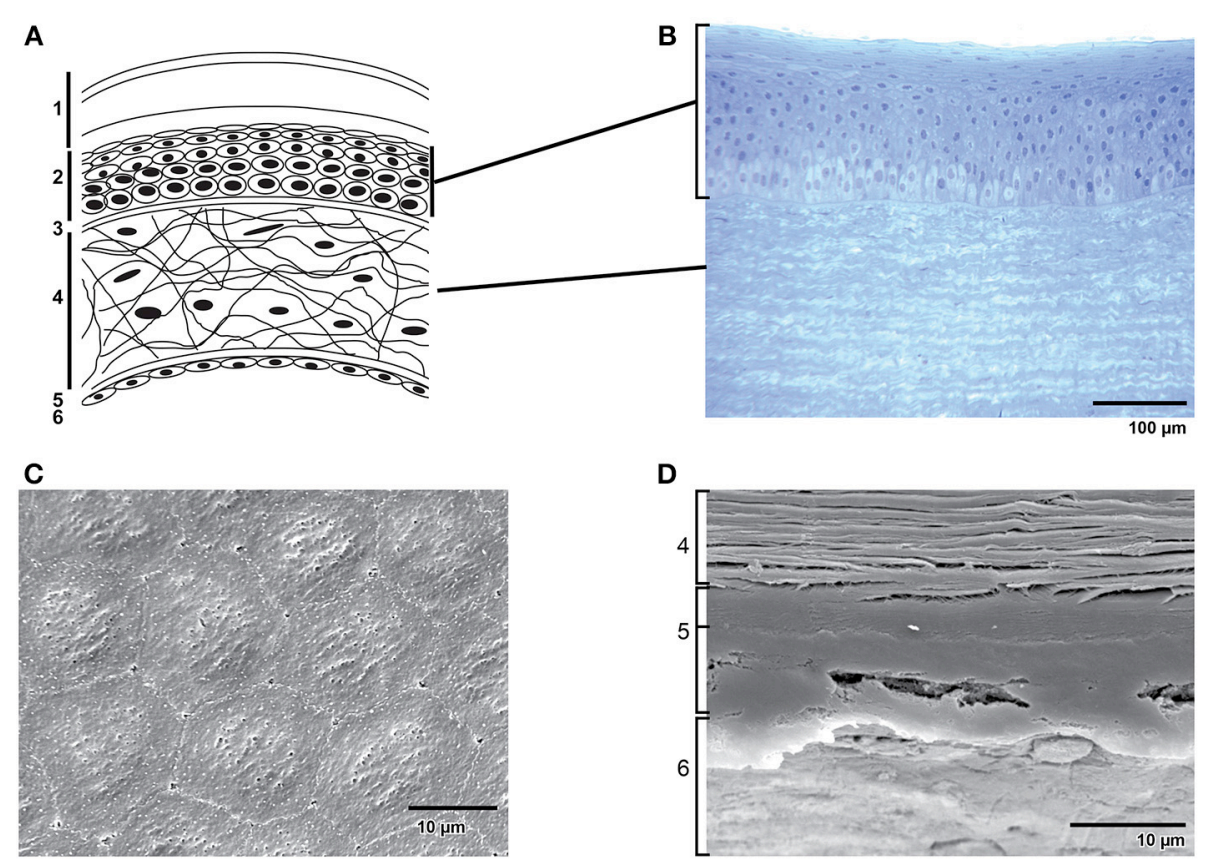

D

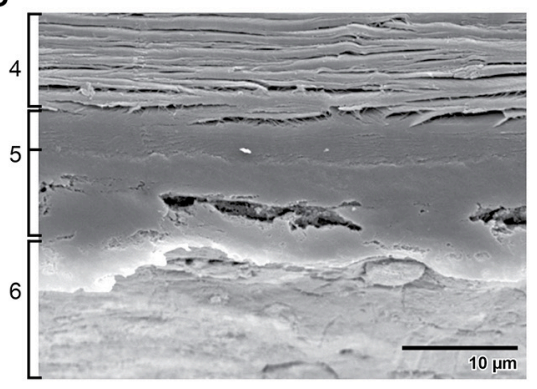

FIGURE 1 | Structure of the cornea. (A) Schematic representation of the structure of the human cornea: 1. Tear film with (starting from the outermost surface) a lipid layer, aqueous layer and a mucous layer. 2. Epithelial cells. 3. Bowman's membrane. 4. Stroma with keratocytes in an extracellular matrix of collagen fibrils and glycoaminoglycans. 5 .

Descemet's membrane. 6. Endothelial monolayer. (B) Transverse section of the epithelium and part of the stroma in bovine cornea. (C) Scanning electron microscopy of bovine corneal endothelium. Note the hexagonal shape of the cells. (D) Scanning electron microscopy of a transverse section of bovine cornea showing (from bottom to top) endothelium (6), the two distinct layers of Descemet's membrane (5) and a part of the stroma (4). fixed focal length and enables focusing light onto the retina of the eye, hereby making the cornea act as an important lens. The avascular nature of the cornea and the regular arrangement of the collagen fibrils of the stroma ensure the transparency of the cornea (Davson, 1949; Dikstein and Maurice, 1972; Maurice, 1972; Hull et al., 1977; Riley, 1985; Bonanno and Giasson, 1992a,b; Bonanno, 2003), which is crucial for good vision. The cornea also serves as a filter, screening out some of the most damaging ultraviolet (UV) wavelengths in sunlight. Without this protection, the lens and the retina would be highly susceptible to injury from UV radiation. The cornea also functions as a barrier against influx of solutes, dust, germs, pathogens, and other injurious matter, into the eye. This protective task is primarily carried out by the epithelium but is shared with the eyelids, the eye socket, tears, and the sclera. Bowman's membrane and Descemet's membrane serve as a protective barrier against infection and injuries (Beuerman and Pedroza, 1996). The corneal epithelium, with its microvilli and microplicae, acts as a mucous surface that absorbs oxygen and nutrients from tears. The endothelium absorbs nutrients from the aqueous humor in order to provide the rest of the cornea of these nutrients.

The main physiological role of the corneal endothelium is maintenance of corneal transparency by controlling stromal hydration (Davson, 1949; Dikstein and Maurice, 1972; Maurice, 1972; Hull et al., 1977; Riley, 1985; Bonanno and Giasson, 1992a,b; Bonanno, 2003). Since the paracellular space between the corneal endothelial cells is partially occluded by the discontinuous focal adhesion tight junctions and the sinuous interdigitations of lateral membranes of adjacent cells, the endothelial barrier is leaky and permits paracellular passage of fluid and nutrients from the aqueous humor into the avascular cornea. The endothelium counteracts the tendency of the corneal stroma to swell by removing excess of stromal fluid and by regulating paracellular permeability through a complex interplay of cellular adhesive forces balanced against counter-adhesive forces generated by actomyosin molecular motors and through an active fluid transport from the stroma into the anterior chamber of the eye (reviewed in Bonanno, 2003). Both the "pump" and barrier functions of the endothelium are essential for maintaining the relatively dehydrated state of the stroma required for transparency. This continuous maintenance of equilibrium is referred to as the pump-leak mechanism (Davson, 1949; Maurice, 1972).

\section{CORNEAL DYSFUNCTION \\ Regulation of barrier integrity}

In order to maintain corneal function, regulation of the barrier integrity is crucial. The barrier function of the endothelial monolayer is controlled by the activation of different signaling mechanisms that affect paracellular and transcellular pathways. Although much is known about the identity of ion transport mechanisms in the corneal endothelium (Bonanno, 2003), the mechanisms of cell signaling that regulate barrier integrity are just beginning to be understood (Riley et al., 1996, 1998; Bonanno, 2003). An increase in contractility of the cortical perijunctional 
actomyosin ring (PAMR) induces a centripetal force that opposes the tethering forces at tight junctions and adherens junctions and results in a breakdown of the endothelial barrier integrity (i.e., an increase in paracellular permeability) (Garcia and Schaphorst, 1995; Turner et al., 1997; Stevenson, 1999; Turner, 2000). The contractility of the actin cytoskeleton, including that of PAMR, is regulated through actomyosin interaction that is induced by the phosphorylation of the regulatory light chain of myosin II, also called myosin light chain (MLC) (Somlyo and Somlyo, 2000; Kamm and Stull, 2001). Phosphorylation of MLC, influenced by MLCK, PKC, or Rho kinase, induces an altered contractility of the actin cytoskeleton (Dudek and Garcia, 2001; Bogatcheva et al., 2002; Satpathy et al., 2004), which results in a significant breakdown of barrier integrity and the formation of interendothelial gaps (Garcia et al., 1995; Zhao and Davis, 1999; Van Nieuw Amerongen et al., 2000; Vouret-Craviari et al., 2002). Restoration of barrier integrity mainly occurs through relaxation of the actin cytoskeleton as a result of a decreased MLC phosphorylation via PKA-mediated inactivation of MLCK (Garcia et al., 1997; Somlyo and Somlyo, 2000; Kamm and Stull, 2001). In BCEC, barrier integrity is controlled via MLCK-, PKC- and Rho kinase-mediated pathways that regulate the MLC phosphorylation status (Satpathy et al., 2004, 2005; Srinivas et al., 2004).

\section{Cell loss}

In humans, corneal endothelial cell count averages around 3000 (Waring et al., 1982) to 6000 (Bourne, 2003) cells $/ \mathrm{mm}^{2}$ at birth and then slowly declines with age (Bourne and Brubaker, 1982, 1983; Bourne et al., 1997). With advancing age corneal endothelial cells also display greater morphological heterogeneity, a smaller percentage of hexagonal cells (Bourne and Brubaker, 1983; Bourne, 2003), and a decreased endothelial cell density and corneal thickness (Armitage et al., 2003; Zhu and Joyce, 2004; Mimura and Joyce, 2006) (for review see Moller-Pedersen, 1997; Bourne, 2001; Joyce, 2003). This cell loss can be accelerated by damage (Bourne and Brubaker, 1982, 1983; Bourne et al., 1997), pathological factors, such as primary corneal endotheliopathies (Schultz et al., 1984; Gagnon et al., 1997) (e.g., Fuchs's dystrophy), inflammation, glaucoma, prolonged UV exposure, a number of drugs and mechanical injury during intraocular surgery (Rao et al., 1978; Brooks and Gillies, 1991; Armitage et al., 2003) or laser procedures (Bergmann et al., 1991).

In the healthy adult cornea, endothelial cell count is between 2000 and 2500 cells $/ \mathrm{mm}^{2}$. When this cell count falls below a critical level (500-1000 cells $\left./ \mathrm{mm}^{2}\right)$ endothelial dysfunction occurs (Edelhauser, 2000; Bonanno, 2003; Bourne, 2003; Bourne and McLaren, 2004; Bourne et al., 2004). Loss of an intact endothelial monolayer induces corneal edema, which causes the cornea to become cloudy, resulting in a loss of visual acuity (Riley, 1985; Landshman et al., 1988; Tuft and Coster, 1990; Riley et al., 1998; George and Larkin, 2004). In this situation, corneal transplantation is required to restore a functional endothelium (George and Larkin, 2004) as there are no pharmacological approaches to overcome endothelial dysfunction.

\section{Wound repair}

In many cell types, including corneal epithelium, cell division contributes to wound repair. However, evidence strongly suggests that cell division, if it occurs, plays only a minor role as a repair mechanism in mature corneal endothelium in vivo. Numerous studies indicate that wound healing in mature corneal endothelium in vivo mainly occurs by cell enlargement, in which flattening of the cells occurs, and cell migration, in which individual cells move from the wound edge to repopulate the wound (for review see Joyce, 2003). As a consequence of this form of repair, there is not only an age-related increase in cell size (polymegathism) of corneal endothelial cells, but also a gradual alteration from the typical hexagonal shape to a more polygonal, and finally pleomorphic shape (pleomorphism) (Laing et al., 1976; Matsubara and Tanishima, 1983; Murphy et al., 1984; Hoppenreijs et al., 1992). Stimulation of the cAMP pathway enhances individual cell migration, and prostaglandin E2 (PGE2) may be an endogenous stimulator of this response during corneal endothelial wound repair (Joyce and Meklir, 1994).

When only a small number of cells have been injured, healing occurs solely by enlargement of cells immediately adjacent to the wound. Repair appears to be initiated by membrane ruffling into the wound area. Once cells have made contact with each other, they stop ruffling and establish mature cell-cell contacts (for review see Joyce, 2003). In large wounds, repair occurs mainly as the result of coordinated enlargement and migration of cells adjacent to the wound and a few rows behind the wound edge. Cells initially enlarge and elongate into the wound area, causing movement of the monolayer as a sheet to cover the wound. Without losing contact with neighboring cells, the enlarged cells subsequently contract and pull surrounding cells into the wound area (Ichijima et al., 1993a,b). This form of repair has been designated as monolayer "spreading" (Joyce et al., 1989). Both monolayer spreading and cell migration result, at least in part, from alterations in the expression and organization of cytoskeletal elements, such as actin filaments and microtubules.

\section{INTERCELLULAR COMMUNICATION IN BOVINE CORNEAL ENDOTHELIAL CELL MONOLAYERS \\ CONNEXIN AND PANNEXIN EXPRESSION PROFILE}

Intercellular communication between bovine corneal endothelial cells typically has been studied using a local mechanically induced stimulus applied to a single cell. Communication between cells can be easily monitored by measuring intercellular $\mathrm{Ca}^{2+}$-wave propagation within the BCEC monolayer that is loaded with a fluorescent $\mathrm{Ca}^{2+}$ dye, Fluo-4. A detailed description and visualized representation of the method can be found elsewhere (D'hondt et al., 2013a). The focus on $\mathrm{Ca}^{2+}$ signaling in this type of experiments is due to the fact that mechanical stimulation elicits an increase in cytosolic $\left[\mathrm{Ca}^{2+}\right]$, involving several $\mathrm{Ca}^{2+}$-flux mechanisms, including the inositol 1,4,5-trisphosphate $\left(\mathrm{IP}_{3}\right)$ receptor $\left(\mathrm{IP}_{3} \mathrm{R}\right)$-mediated release of $\mathrm{Ca}^{2+}$ from the endoplasmic reticulum due to the activation of phospholipase $\mathrm{C}$ (PLC) (Leybaert and Sanderson, 2012; D'hondt et al., 2013a) (Figure 2A). A detailed analysis of the spatio-temporal activation of PLC upon mechanical stimulation has been described by others in MDCK cells (Tsukamoto et al., 2010), although the 


\section{A}
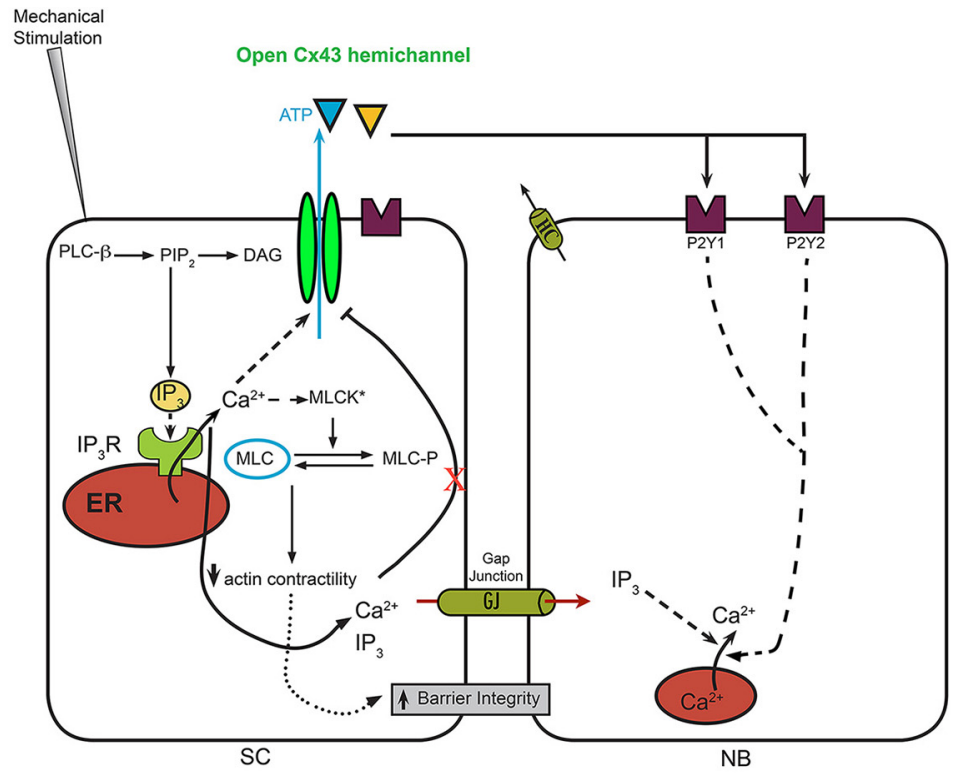

B

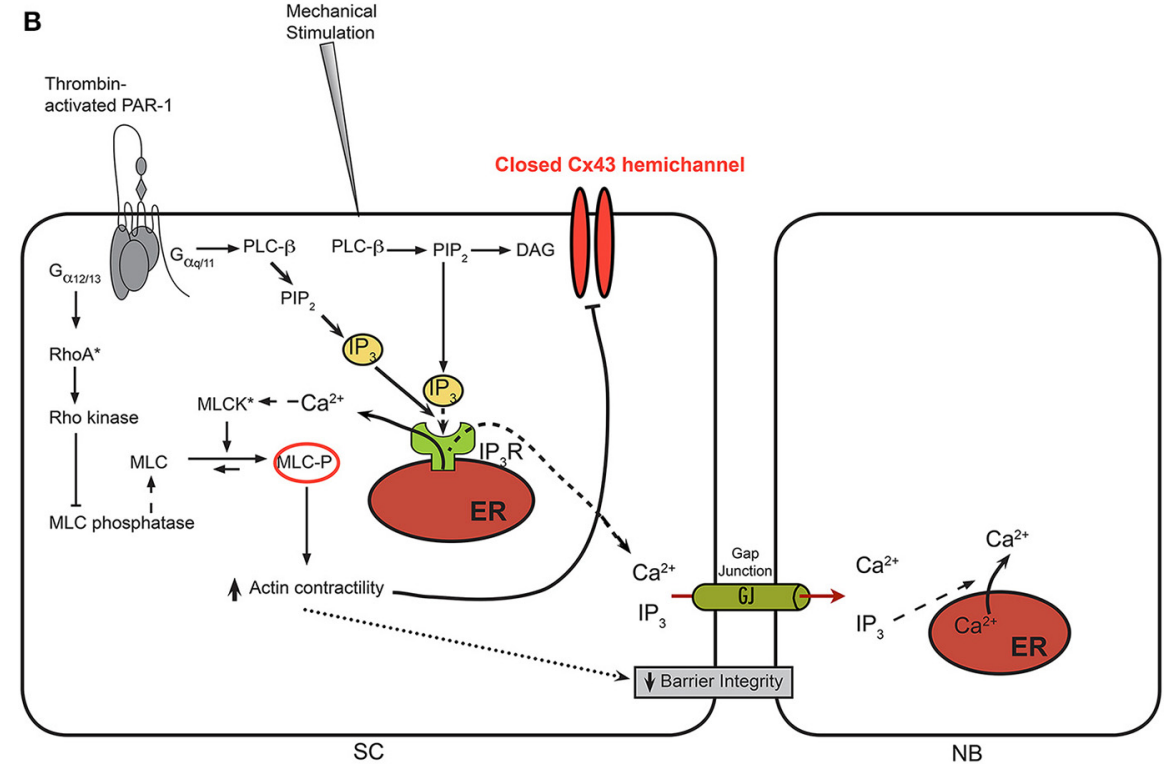

$\mathrm{SC}$

NB

FIGURE 2 | A model for $\mathrm{Ca}^{2+}$-wave propagation in BCECs in normal conditions vs. thrombin-treated conditions. (A) In normal BCECs, it is hypothesized that mechanical stimulation leads to a moderate rise in cytosolic $\left[\mathrm{Ca}^{2+}\right]$ via $\mathrm{IP}_{3}$-dependent signaling mechanisms, which leads to the opening of $\mathrm{C} \times 43$ hemichannels and the flux of ATP from the cytosol into the extracellular environment. This allows the propagation of the $\mathrm{Ca}^{2+}$ from the "stimulated cell" (SC) to neighboring (NB) cells via activation of purinergic receptor and downstream $\mathrm{IP}_{3}$-induced $\mathrm{Ca}^{2+}$ signaling. Under these conditions, it is anticipated that MLC remains in a dephosphorylated state, because of excess MLC phosphatase activity despite the potential activation of MLC kinases through $\mathrm{Ca}^{2+} / \mathrm{CaM}$. (B) In thrombin-pre-treated BCECs, the concerted activation of $\mathrm{IP}_{3} / \mathrm{Ca}^{2+}$ signaling, leading to the activation MLC kinase combined with the activation RhoA/Rho kinase, leading to the inhibition of MLC phosphatase, leads to an enhanced contractility of the actin/myosin cytoskeleton. The latter seems linked to the Cx43 hemichannels, likely through its C-terminal tail. Increased actin/myosin contractility is proposed to displace the $\mathrm{C}$-terminal tail from the cytoplasmic loop, thereby annihilating loop/tail interactions essential for Cx43-hemichannel opening. As such, $\mathrm{Ca}^{2+}$ signaling triggered by mechanical stimulation will not be able to lead to opening of these "locked"/'closed" Cx43 hemichannels, preventing extracellular ATP release and suppressing ATP-driven $\mathrm{Ca}^{2+}$-wave propagation to neighboring cells. In addition to the effects of the actin/myosin contractility on Cx43 hemichannels, actin/myosin contractility may alter tight junctions and the ability of "head-to-head" docked hemichannels to form gap junction channels. exact mechanisms underlying this PLC activation remain elusive. Importantly, the properties of the intercellular $\mathrm{Ca}^{2+}$ wave, including the speed of propagation and the extent of propagation (i.e., active area, corresponding to the area of cells responding with a cytosolic $\left[\mathrm{Ca}^{2+}\right]$ rise) provide an invaluable tool to analyze the properties of communicating channels, like connexins and pannexins (Leybaert and Sanderson, 2012). Furthermore, the occurrence of intercellular $\mathrm{Ca}^{2+}$ waves has been described 
in a variety of cell systems and tissues, including the retina, cochlea, blood vessels, brain, liver with important physiological functions and pathophysiological consequences (Leybaert and Sanderson, 2012). Furthermore, the method impinges on the endogenously expressed channels and receptors and physiological signaling molecules present within the primary cell system. In particular, the presence of different connexin isoforms, including Cx26, Cx30.3, Cx31, Cx32, Cx36, Cx43, Cx45, Cx46, Cx46.6, and Cx50 and pannexin isoforms, including Panx1, Panx2, and Panx3, has been confirmed at the mRNA level (Ponsaerts et al., 2010a). At the protein level, the presence of $\mathrm{Cx} 43$ in BCEC lysates could be demonstrated via immunoblotting (Ponsaerts et al., 2010b), while immunocytochemistry showed the presence of Cx26 and Cx43 between corneal endothelial cells (Laux-Fenton et al., 2003). While these observations do not allow making conclusions about the relative expression of $\mathrm{Cx} / \mathrm{Panx}$ isoforms or about the predominant $\mathrm{Cx} / \mathrm{Pan}$ isoforms, the presence of a plethora of $\mathrm{Cx} / \mathrm{Panx}$ isoforms do underpin that BCECs are very well suited for studying intercellular communication. Furthermore, these aspects are not limited to BCECs, since human corneal endothelial cells also express connexin isoforms, including $\mathrm{Cx} 43$, and display intercellular communication (Williams and Watsky, 2002). The upregulation of $\mathrm{Cx} 43$ at the protein level seems an important marker for the assessment of novel strategies to improve the preservation and maintenance of functional human donor cornea. In particular, the treatment with vasoactive intestinal peptide and ciliary neurotrophic factor, endogenous autocrine molecules from corneal endothelial cells, seem to be very promising agents to promote the differentiation and survival of corneal endothelial cells (Koh et al., 2011; Koh, 2012). Finally, the presence of connexins in corneal endothelial cells also seems to prevent their proliferation. As such, Cx43 knockdown has been implicated as a novel therapeutic strategy to accelerate wound healing in the corneal endothelium (Nakano et al., 2008) and to promote re-epithelialization by suppressing stromal oedema and inflammatory responses (Grupcheva et al., 2012).

\section{PARACRINE SIGNALING}

Intercellular communication, including intercellular $\mathrm{Ca}^{2+}$-wave propagation, can occur via two main pathways: (i) direct coupling via gap junction channel, allowing the passage of signaling molecules that can mobilize intracellular $\mathrm{Ca}^{2+}$, like $\mathrm{IP}_{3}$, and (ii) indirect coupling via hemichannels, allowing the release of signaling molecules, like ATP, that can trigger intracellular $\mathrm{Ca}^{2+}$ signaling by acting on ionotropic and/or metabotropic receptors, like the $\mathrm{P} 2 \mathrm{X}$ and $\mathrm{P} 2 \mathrm{Y}$ purinergic receptors (Leybaert and Sanderson, 2012) (Figure 2A). In BCECs, a prominent role for paracrine signaling via extracellular ATP was found as the main driving mechanism for intercellular $\mathrm{Ca}^{2+}$-wave propagation in response to mechanical stimulation (Gomes et al., 2005b), although gap junctions are present and are operative in BCECs (Gomes et al., 2006). Indeed, exogenous application of the apyrase VI + VII cocktail dramatically diminished the active area of the intercellular $\mathrm{Ca}^{2+}$-wave (Figure 3 ), while inhibiting endogenously expressed ectonucleotidases using exogenously applied inhibitors, like ARL-67156, dramatically increased the intercellular communication (Gomes et al., 2005b).

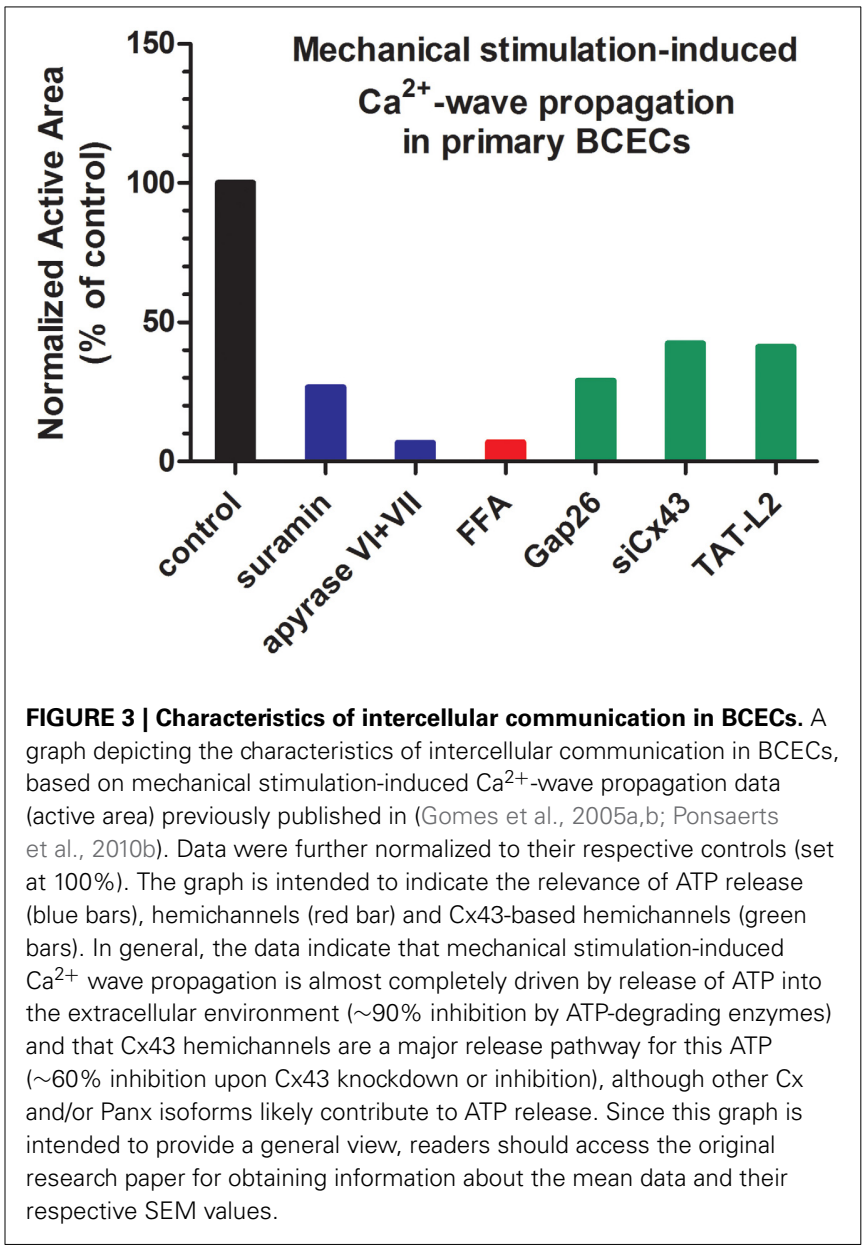

These observations were supported by direct luciferin/luciferase bioluminescent measurements of the extracellular ATP levels, showing that mechanical stimulation induced ATP release in the extracellular environment. Extracellular ATP-driven intercellular $\mathrm{Ca}^{2+}$-wave propagation requires the presence of ATP receptors that initiate $\mathrm{Ca}^{2+}$ signaling upon activation. At the mRNA level, different ionotropic $\mathrm{P} 2 \mathrm{X}$ receptors, including $\mathrm{P} 2 \mathrm{X} 3, \mathrm{P} 2 \mathrm{X} 4, \mathrm{P} 2 \mathrm{X} 5$, and $\mathrm{P} 2 \mathrm{X} 7$ and different metabotropic $\mathrm{P} 2 \mathrm{Y}$ receptors, including $\mathrm{P} 2 \mathrm{Y} 1, \mathrm{P} 2 \mathrm{Y} 2, \mathrm{P} 2 \mathrm{Y} 4, \mathrm{P} 2 \mathrm{Y} 6, \mathrm{P} 2 \mathrm{Y} 10$, and $\mathrm{P} 2 \mathrm{Y} 12$ are expressed (Gomes et al., 2005b; Ponsaerts et al., 2010a), correlating with previous functional evidence (Srinivas et al., 1998). Also mRNA of the ectonucleotidases, CD39 and CD73, was detected, confirming the presence of ATP-degrading enzymes. The activity of ectonucleotidases seems to critically control this ATP-driven communication, since aged BCECs display increased ectonucleotidase activity and concomittant reduced ATP-dependent intercellular communication (D'hondt et al., 2009). Consistent with the presence of the purinergic receptors, exogenously added ATP using concentrations in the (sub) $\mu \mathrm{M}$ range was able to induce intracellular $\mathrm{Ca}^{2+}$ release with an EC50 of $\sim 1.5 \mu \mathrm{M}$. Particularly, P2Y receptors might be responsible for the ATP-induced $\mathrm{Ca}^{2+}$ rises and ATP-driven $\mathrm{Ca}^{2+}$-wave propagations, since suramin, a nonselective $\mathrm{P} 2 \mathrm{X}$ and $\mathrm{P} 2 \mathrm{Y}$ antagonist, dramatically reduced intercellular $\mathrm{Ca}^{2+}$-wave propagation (Gomes et al., 2005b) (Figure 3). 
However, the latter result should be interpreted with caution, since a recent report indicated that suramin could also suppress Cx43-hemichannel activity and its associated membrane permeability (Chi et al., 2014).

\section{Cx43 HEMICHANNELS}

An important mechanism responsible for the release of ATP seems to be mediated via hemichannels (Gomes et al., 2005a). Similar to the application of exogenous apyrases, the presence of flufenamic acid (FFA), a known hemichannel inhibitor, strongly reduced mechanical stimulation-induced $\mathrm{Ca}^{2+}$-wave propagation in BCECs and almost completely blunted mechanical stimulation-induced ATP release without affecting gap junction coupling (Gomes et al., 2005a) (Figure 3). Yet, data obtained using FFA have to be interpreted with caution, since FFA is a broad spectrum ion channel modulator, impacting a variety of non-selective cation channels and $\mathrm{K}^{+}, \mathrm{Ca}^{2+}, \mathrm{Na}^{+}$and $\mathrm{Cl}^{-}$permeable channels (see Guinamard et al., 2013 for a detailed discussion). Consistent with the prominent expression of $\mathrm{Cx} 43$ in BCECs and the relevance of $\mathrm{Cx} 43$ as one of the major $\mathrm{Cx}$ isoforms responsible for intercellular communication and intercellular $\mathrm{Ca}^{2+}$ waves, Gap26, a Cx43-mimetic peptide, suppressed intercellular communication and ATP release (Gomes et al., 2005a) (Figure 3). It is important to note that Gap26 can also inhibit gap junction-mediated intercellular communication. However, as shown in a recent electrophysiological study, the kinetics for inhibition of hemichannels vs. gap junctions by Gap26 seems to be very different. Indeed, short-term incubations ( $\sim 5 \mathrm{~min})$ were sufficient to readily inhibit $\mathrm{Cx} 43$-hemichannel currents, while long-term incubations $(\sim 30 \mathrm{~min})$ were required to inhibit $\mathrm{Cx} 43$ gap junction-mediated electrical coupling in cell pairs (Desplantez et al., 2012). The inhibition of $\mathrm{Cx} 43$ hemichannels by Gap26 has been further characterized, displaying a right-ward shift of about $20-30 \mathrm{mV}$ for the activation of Cx43 hemichannel currents, suppressing Cx43-hemichannel currents potentiated by physiological elevations in intracellular $\left[\mathrm{Ca}^{2+}\right]$, and inhibiting Cx43-hemichannel currents with an IC50 of about $80 \mu \mathrm{M}$ (Wang et al., 2012, 2013a). Not only ectopically expressed $\mathrm{Cx} 43$ hemichannels could be inhibited, but Gap26 also suppressed native $\mathrm{Cx} 43$ hemichannels from pig ventricular cardiomyocytes (Wang et al., 2012). In BCECs, Gap26 applications that are able to inhibit $\mathrm{Cx} 43$ hemichannels did not impair gap junctional coupling in fluorescence recovery after photobleaching (FRAP) using carboxyfluorescein (Gomes et al., 2005a). More recently, siRNA-based knock down approaches were applied to directly assess the contribution of $\mathrm{Cx} 43$ in this process (Ponsaerts et al., 2010b) (Figure 3). Reducing the endogenous $\mathrm{Cx} 43$-protein levels by about $90 \%$ resulted in a more than $70 \%$ reduction in the active area of the intercellular $\mathrm{Ca}^{2+}$ wave in response to mechanical stimulation. Also using $\mathrm{Ca}^{2+}$-free solution (EGTA) as a trigger for the opening of hemichannels, the knockdown of $\mathrm{Cx} 43$ resulted in a more than $60 \%$ reduction in EGTA-induced ATP release. Collectively, these data indicate $\mathrm{Cx} 43$ as the main connexin isoform responsible for forming hemichannels and for mediating hemichannel-mediated ATP release in BCECs, thereby driving intercellular $\mathrm{Ca}^{2+}$-wave propagation.

\section{BOVINE CORNEAL ENDOTHELIAL CELL MONOLAYERS AS A PRIMARY CELL MODEL FOR THE STUDY OF CX43-HEMICHANNEL PROPERTIES AND REGULATION CX43 HEMICHANNELS AS INTEGRATORS OF SIGNALING PROCESSES}

Cx43 hemichannels can be activated via membrane depolarizations, decreases in extracellular $\left[\mathrm{Ca}^{2+}\right]$ and moderate increases in intracellular $\left[\mathrm{Ca}^{2+}\right]$ (Wang et al., 2013a,c). While strong membrane depolarization (above $+50 \mathrm{mV}$ ) are needed for the opening of $\mathrm{Cx} 43$ hemichannels, increases in cytosolic $\left[\mathrm{Ca}^{2+}\right]$ in the physiological range of $100-500 \mathrm{nM}$ provoke a left-ward shift in the voltage-dependent opening of $\mathrm{Cx} 43$ hemichannels (Wang et al., 2012). In this study, moderate intracellular $\left[\mathrm{Ca}^{2+}\right]$ elevations could induce $\mathrm{Cx} 43$-hemichannel opening in response to a membrane depolarization in the order of $+30 \mathrm{mV}$, thus shifting the threshold for voltage activation toward the physiological range (Wang et al., 2012). Furthermore, increasing the cytosolic $\left[\mathrm{Ca}^{2+}\right]$ to about $500 \mathrm{nM}$ seems sufficient to open Cx43 hemichannels, allowing the flux of ions and of signaling molecules like ATP (De Vuyst et al., 2009). In that sense, it is not surprising that mechanical stimulation, which triggers cytosolic $\mathrm{Ca}^{2+}$ rises, leads to $\mathrm{Cx} 43$ hemichannel opening. Furthermore, this Cx43-hemichannel opening seems to be strongly influenced by other physiological signaling cascades in response to extracellular factors. For instance, activation of the plasmalemmal thrombin-sensitive PAR-1 receptors using thrombin or the thrombin receptor activating peptide 6 (TRAP6; SFLLRN) inhibited Cx43-hemichannel activity in BCECs in response to mechanical stimulation (D'hondt et al., 2007a) (Figure 2B). The underlying signaling cascades triggered by thrombin exposure involved the concerted activation of myosin light chain kinase (MLCK), Rho kinase and protein kinase C (PKC) (Garcia et al., 1996; D'hondt et al., 2007a) (Figure 2B). Separate inhibition of one of the signaling cascades nearly completely restored $\mathrm{Cx} 43$ hemichannel opening in thrombin-treated BCECs. A common denominator of the different signaling pathways initiated by thrombin is that they all contribute to increased myosin light chain (MLC) phosphorylation (Satpathy et al., 2004), an event that results in increased contractility of the actin cytoskeleton in non-muscle cells (Burridge and Chrzanowska-Wodnicka, 1996). The critical role of the MLC phosphorylation status for controlling Cx43-hemichannel activity has been supported by experiments applying adenosine (D'hondt et al., 2007b), which has previously been demonstrated to induce MLC dephosphorylation in BCEC (Srinivas et al., 2004). Extracellularly added adenosine counteracts RhoA activation via a cAMP-dependent mechanism, prevents the inhibition of MLC phosphatase and opposes thrombin-induced MLC phosphorylation (D'hondt et al., 2007b). Interestingly, pre-incubation of the BCECs with adenosine completely alleviated the thrombin-induced inhibition of $\mathrm{Cx} 43$ hemichannels. The critical role of RhoA in the downstream signaling cascade initiated by thrombin and cross-talk to $\mathrm{Cx} 43$ hemichannels was supported by the use of C3 toxin, a cellpermeable RhoA inhibitor (Ponsaerts et al., 2012a). This compound completely abolished the thrombin-induced inhibition of Cx43 hemichannels in BCECs. Consistent with this, RhoA was rapidly activated in BCECs exposed to thrombin and $\mathrm{C} 3$ toxin pre-treatment completely prevented this RhoA activity. 


\section{CX43-HEMICHANNEL OPENING IS NEGATIVELY REGULATED BY THE ACTIN CYTOSKELETON}

Given the prominent role of MLC phosphorylation in controlling the contractility of the actin/myosin cytoskeleton and the functional link between MLC phosphorylation and decreased Cx43 hemichannel activity, the impact of the actin/myosin contractility on Cx43-hemichannel opening was assessed using a myosin II ATPase inhibitor, (-)-blebbistatin (Straight et al., 2003; Ponsaerts et al., 2008). This compound prevents the contraction of the actin/myosin cytoskeleton (Straight et al., 2003; Lucas-Lopez et al., 2008). Importantly, (-)-blebbistatin does not prevent the thrombin-induced increase in the MLC phosphorylation status, indicating that it does not affect the upstream signaling pathways controlling the activity of kinases or phosphatases that impact the MLC phosphorylation status (Ponsaerts et al., 2008). Strikingly, (-)-blebbistatin completely prevented the thrombin-induced inhibition of $\mathrm{Cx} 43$ hemichannel activity in BCECs brought about either mechanical stimulation or by $\mathrm{Ca}^{2+}$-free solution. These data indicated that activation of the actomyosin contractile system serves as an endogenous brake counteracting the opening of Cx43 hemichannels (Ponsaerts et al., 2012b). The negative regulation of $\mathrm{Cx} 43$ hemichannels seems not restricted to BCECs, but seems to be a generally present and physiologically relevant mechanism (Ponsaerts et al., 2010b). Indeed, follow-up work in HeLa cells and C6 glioma cells ectopically expressing $\mathrm{Cx} 43$ revealed a bell-shaped dependent regulation of Cx43-hemichannel activity in response to cytosolic $\left[\mathrm{Ca}^{2+}\right]$. Moderate rises in cytosolic $\left[\mathrm{Ca}^{2+}\right]$ in the range of $100-500 \mathrm{nM}$ triggered $\mathrm{Cx} 43$-hemichannel opening, while excessive rises in cytosolic $\left[\mathrm{Ca}^{2+}\right]$ above $500 \mathrm{nM}$ and the $\mu \mathrm{M}$ range suppressed Cx43-hemichannel opening (De Vuyst et al., 2009; Ponsaerts et al., 2010b). Interestingly, the inhibition of Cx43-hemichannel opening brought about by high cytosolic $\left[\mathrm{Ca}^{2+}\right]$ rises (triggered by $10 \mu \mathrm{M}$ A23187, a $\mathrm{Ca}^{2+}$ ionophore) could be completely prevented by (-)-blebbistatin (Ponsaerts et al., 2010b). This mechanism may not only occur during steady-state rises in cytosolic $\left[\mathrm{Ca}^{2+}\right]$, but may also occur during physiological agonist-induced $\mathrm{Ca}^{2+}$ signaling (De Bock et al., 2012b). In recent work, it was shown that bradykinin-triggered $\mathrm{Ca}^{2+}$ oscillations in the MDCK epithelial cell line led to the $\mathrm{Ca}^{2+}$-dependent opening of Cx43 hemichannels (De Bock et al., 2012b). Interestingly, the opening of Cx43 hemichannels provided a non-selective $\mathrm{Ca}^{2+}$-entry pathway and led to a further rise in cytosolic $\left[\mathrm{Ca}^{2+}\right]$, causing inhibition of Cx43-hemichannel opening. Thus, it may be anticipated that activation of the actomyosin cytoskeleton may have dual function: (i) by acting as a "safety" mechanism to prevent excessive Cx43-hemichannel opening, which would be detrimental for the cell due to loss of ionic, metabolic and energetic gradients, and (ii) by serving as a " $\mathrm{Ca}^{2+}$-dependent" shutdown mechanism of $\mathrm{Cx} 43$ hemichannels, allowing a bimodal regulation of $\mathrm{Cx} 43$-hemichannel opening by cytosolic $\left[\mathrm{Ca}^{2+}\right]$. The $\mathrm{Ca}^{2+}$-dependent inhibition of $\mathrm{Cx} 43$ hemichannels promotes the occurrence of sustained $\mathrm{Ca}^{2+}$ oscillations, leading to increased survival [e.g., by increasing mitochondrial bioenergetics (Hajnoczky et al., 1995)] or controlling physiological functions like endothelial cell membrane permeability (De Bock et al., 2012a, 2013). In the absence of $\mathrm{Ca}^{2+}$-dependent inhibition of Cx43 hemichannels, the $\mathrm{Ca}^{2+}$-dependent opening of $\mathrm{Cx} 43$ hemichannels could lead to a sustained $\mathrm{Ca}^{2+}$ influx, causing intracellular $\mathrm{Ca}^{2+}$ overload and cell death.

Different mechanisms responsible for the negative regulation of $\mathrm{Cx} 43$ hemichannels by the actin/myosin contractile systems may be considered, including a direct or indirect link between Cx43 hemichannels and the actin/myosin cytoskeleton (Ponsaerts et al., 2012b). Unfortunately, while many cytoskeletal proteins have been shown to interact with $\mathrm{Cx} 43$, most, if not all, evidence has been obtained for $\mathrm{Cx} 43$ gap junctions (Herve et al., 2012). In that sense, it is interesting to note that increased contractility also negatively impacted $\mathrm{Cx} 43$-mediated gap junctional coupling in BCECs (D’hondt et al., 2007a). One of the underlying mechanisms proposed was the loss of tethering forces essential for stabilizing the interactions of the transmembrane proteins of tight junctions and the subsequent disrupted barrier integrity (Garcia et al., 1996; Satpathy et al., 2004). Hence, sufficient level of tethering forces may facilitate the docking of hemichannels from adjacent cells to form and maintain gap junction channels. Another aspect proposed was that increased actin/myosin contractility could interfere with the interaction of Zona Occludens-1 (ZO-1) with $\mathrm{Cx} 43$, thereby affecting $\mathrm{Cx} 43$ gap junction assembly (Hunter et al., 2005; Rhett et al., 2011). Loss of Cx43/ZO-1 interaction has been shown to increase gap junction size (Hunter et al., 2005). This promoted the trafficking of and assembly of the "undocked" hemichannels from the perinexus into gap junctional plaques, thereby increasing gap junctional communication while decreasing hemichannel-mediated signaling (Rhett et al., 2011). In BCECs, the binding of $\mathrm{ZO}-1$ to $\mathrm{Cx} 43$ hemichannels was not detectable. In addition, it seemed that the inhibition of hemichannel opening by thrombin could be overcome by both TAT-CT10 and TAT-CT10 $\Delta \mathrm{I}$, which lacks the last Ile residue critical for binding the PDZ2 domain of ZO-1 (Giepmans and Moolenaar, 1998; Ponsaerts et al., 2010b). Furthermore, the loss of tethering forces and barrier integrity could definitely not account for an inhibition of $\mathrm{Cx} 43$-hemichannel activity, since such an effect may rather lead to an increase in the ratio of "undocked" $\mathrm{Cx} 43$ hemichannels over docked $\mathrm{Cx} 43$ gap junctions. While it is clear that actin contractility negatively impacts $\mathrm{Cx} 43$-hemichannel activity, proper cytoskeletal organization is definitely required for ATP release and subsequent intercellular $\mathrm{Ca}^{2+}$ signaling, since these phenomena are impaired upon cytoskeletal destabilization using cytochalasin D exposure (Cotrina et al., 1998).

\section{CX43 HEMICHANNEL OPENING IS CONTROLLED BY INTRAMOLECULAR LOOP/TAIL INTERACTIONS}

Since $\mathrm{Cx} 43$ gap junctions are critically and dynamically controlled by intramolecular interactions between the C-terminal tail and the second part of the cytoplasmic loop (L2 region) (Duffy et al., 2002; Delmar et al., 2004; Seki et al., 2004; Hirst-Jensen et al., 2007) and since Cx43 hemichannels consists of the same protein building blocks as $\mathrm{Cx} 43$ gap junctions, it was plausible that $\mathrm{Cx} 43$-hemichannel opening too was influenced by loop/tail interactions and that the actin/myosin cytoskeleton could impact Cx43-hemichannel activity by interfering with loop/tail interactions. An important insight was provided by the application of cell-permeable peptides covering the last 10 amino acids of the 
C-terminal tail of Cx43 (TAT-CT10) (Ponsaerts et al., 2010b). These residues harbor two important functional domains: (i) the C-terminal $\mathrm{Ile}^{382}$, which serves as the binding site for the PDZ2 domain of ZO-1 (Giepmans and Moolenaar, 1998), and (ii) the $\mathrm{Asp}^{378}$ and $\mathrm{Asp}^{379}$ residues, which serve as residues involved in the interaction with the L2 domain (Hirst-Jensen et al., 2007). Strikingly, pre-incubation of BCECs with TAT-CT10 peptide completely prevented the thrombin-induced inhibition of Cx43 hemichannels (Ponsaerts et al., 2010b). On the one hand, a TAT-CT10 peptide but lacking the C-terminal Ile residue (TAT$\mathrm{CT} 10 \Delta \mathrm{I})$ remained capable of alleviating the thrombin-induced inhibition of $\mathrm{Cx} 43$-hemichannel activity, indicating that altered Cx43/ZO-1-complex formation was not involved in this process (Ponsaerts et al., 2010b). On the other hand, a TAT-CT10 version in which $\mathrm{Asp}^{378}$ and $\mathrm{Asp}^{379}$ have been mutated to Ala residues completely lost its ability to alleviate the thrombin-induced inhibition of Cx43-hemichannel activity (D'hondt et al., 2013b). Consistent with this, while biotinylated CT10 peptides immobilized to a streptavidin-coated sensor chip could bind the L2 and cytoplasmic loop region in surface plasmon resonance experiments, biotinylated CT10 peptides in which $\mathrm{Asp}^{378}$ and $\mathrm{Asp}^{379}$ were changed into Ala residues, completely lost this property (Ponsaerts et al., 2010b; D'hondt et al., 2013b). Similar findings were observed for $\mathrm{Cx} 43$ hemichannels ectopically expressed in HeLa and C6 glioma cells. Indeed, the inhibition of ectopically expressed $\mathrm{Cx} 43$ hemichannels by high cytosolic $\left[\mathrm{Ca}^{2+}\right]$ could be alleviated by treatment of the cells with either TAT-CT10 or TATCT10 $\Delta$ I but not with TAT-CT10 DD/AA (Ponsaerts et al., 2010b). Furthermore, the electroporation of a peptide covering the last 9 amino acids of the C-terminal tail of Cx43 (CT9) in MDCK cells completely abolished the occurrence of bradykinin-induced $\mathrm{Ca}^{2+}$ oscillations (De Bock et al., 2012b). This indicates that the loss of endogenous loop/tail interactions can occur during physiological $\mathrm{Ca}^{2+}$ signaling and is the underlying mechanism responsible for the $\mathrm{Ca}^{2+}$-dependent inhibition of $\mathrm{Cx} 43$ hemichannels.

Since the $\mathrm{L} 2$ region was identified as the target for the CT10 peptide, the effect of a cell-permeable L2 peptide on Cx43 hemichannel opening was also examined (Ponsaerts et al., 2010b). It was found that TAT-L2 prevented Cx43-hemichannel opening in BCECs induced by mechanical stimulation or by $\mathrm{Ca}^{2+}$-free solution (Figure 3). TAT-L2 also inhibited Cx43-hemichannel opening in Cx43-expressing HeLa/C6-glioma cells induced by moderate increases in cytosolic $\left[\mathrm{Ca}^{2+}\right]$. Interestingly, a mutant version of TAT-L2 (i.e., TAT-L2 ${ }^{\mathrm{H} 126 \mathrm{~K} / \mathrm{I} 130 \mathrm{~N}}$ ) previously shown to be impaired for its ability to interact with the C-terminal tail (Seki et al., 2004), failed to inhibit the activity of endogenously and ectopically expressed Cx43 hemichannels (Ponsaerts et al., 2010b). In contrast, gap junctional coupling did not seem to be inhibited by TAT-L2. Hence, it is proposed that TAT-L2 by targeting the CT10 region of $\mathrm{Cx} 43$ hemichannels interferes with the occurrence of endogenous loop/tail interactions essential for Cx43-hemichannel activity. As such, the inhibitory effect of TAT-L2 could be prevented by co-application of TAT-CT10 (Ponsaerts et al., 2010b). Moreover, from these measurements and previous studies of the Delmar group (Seki et al., 2004), it also became clear that L2 oppositely affects $\mathrm{Cx} 43$ gap junctions, namely favoring their open state, while preventing/inhibiting
Cx43 hemichannel opening. These findings were supported by the fact that $\mathrm{Cx} 43^{\mathrm{M} 239}$-based hemichannels, which lack the complete C-terminal tail, fail to open. In contrast, $\mathrm{Cx} 43^{\mathrm{M} 239}$-based gap junctions are active and remain open, even during conditions of acidification (Moreno et al., 2002). Therefore, it was anticipated that loop/tail interactions present in $\mathrm{Cx} 43$ gap junctions also exist in Cx43 hemichannels but with a functional outcome. To scrutinize this concept, it was shown that TAT-CT10 and TAT-CT10 $\Delta$ I, but not TAT-CT10 $\mathrm{DD} / \mathrm{AA}$, could restore $\mathrm{Cx} 43^{\mathrm{M} 239}$-hemichannel activity (Ponsaerts et al., 2010b). It is important to note that the addition of TAT-CT10 is not sufficient to open Cx43 hemichannels, but rather facilitates their opening in response to triggers like voltage steps to positive membrane potentials or increased cytosolic $\left[\mathrm{Ca}^{2+}\right]$. Hence, our model proposes that loop/tail interactions are required to bring $\mathrm{Cx} 43$ hemichannel in a "ready to open" state (Wang et al., 2013a).

Further studies revealed a stretch of 9 amino acids within the L2 region of the cytoplasmic loop as the target of CT10 (Wang et al., 2013b). This Lys-rich stretch of amino acids is mainly positively charged, thereby allowing electrostatic interactions with the two negatively charged Asp residues within the CT10 region. Strikingly, a nonapeptide, called Gap19, displayed similar properties as TAT-L2, thereby causing inhibition of $\mathrm{Cx} 43$ hemichannels but not Cx43 gap junctions (Wang et al., 2013b). Gap19 naturally displayed strong cell-permeable properties, likely due to the Lys-rich stretch, thereby resembling the positively charged residues in the TAT cell-penetrating sequence. Consistent with this, Gap19 completely mimicked the actions of TAT-L2, thereby inhibiting the opening of $\mathrm{Cx} 43$ hemichannels in response to low extracellular $\left[\mathrm{Ca}^{2+}\right]$ or moderate rises in cytosolic $\left[\mathrm{Ca}^{2+}\right]$ (Wang et al., 2013b). The inhibitory effect of Gap19 was also analyzed at the electrophysiological level using whole cell patch clamp experiments, allowing the characterization of its effect on Cx43 hemichannel unitary currents (Wang et al., 2013a,b). Gap19 decreased the frequency of single Cx43-hemichannel openings, thereby reducing the open probability of the Cx43 hemichannels. Interestingly, Gap19 was also found to inhibit native $\mathrm{Cx} 43$ hemichannels present in ventricular cardiomyocytes, acutely isolated from pig hearts. The inhibition seems to be due to a right-shift of about $30 \mathrm{mV}$ in the voltage-dependent opening of Cx43 hemichannels.

Finally, it is anticipated that the loss of loop/tail interactions essential for $\mathrm{Cx} 43$-hemichannel activity may underlie the inhibition of $\mathrm{Cx} 43$-hemichannel activity in response to increased actin/myosin contractility. Indeed, $\mathrm{C} \times 43^{\mathrm{M} 239}$-based hemichannels fail to open, even in response of the myosin II ATPase inhibitor, (-)-blebbistatin (Ponsaerts et al., 2010b).

\section{TARGETING LOOP/TAIL INTERACTIONS IN Cx43: SELECTIVE CX43-HEMICHANNEL INHIBITORS AS NOVEL TOOLS IN CELL BIOLOGY, PHYSIOLOGY AND PATHOPHYSIOLOGY}

The concept of loop/tail interactions differentially controlling Cx43 gap junctions vs. hemichannels has spurred the development of peptide tools, including TAT-L2 and Gap19, to selectively inhibit $\mathrm{Cx} 43$ hemichannels while unaffecting $\mathrm{Cx} 43$ gap junctions in a variety of primary cell systems and tissues (Evans et al., 2012; Iyyathurai et al., 2013; Wang et al., 2013a). As such, these 
tools supplement knockdown/knockout approaches, which do not allow discriminating between gap junctions and hemichannels. Furthermore, these tools are not only selective for $\mathrm{Cx} 43$ hemichannels vs. gap junctions, but are also unlikely to target other Cx or Panx isoforms. In particular, the L2 region of $\mathrm{Cx} 43$ is very divergent among different $\mathrm{Cx}$ isoforms and the region that is targeted by L2 or Gap19, i.e., the last 10 amino acids of $\mathrm{Cx} 43$, is not present in other Cx isoforms (see Table 2 in Iyyathurai et al., 2013 for the BLAST results obtained by using the L2 and CT10 sequences of human $\mathrm{Cx} 43$ as sources). This is supported by experimental evidence, showing that Gap19 did neither inhibit Cx40 hemichannels nor Panxl channels (Wang et al., 2013b).

These tools now set the stage for the discovery of novel cell biological and physiological roles for $\mathrm{Cx} 43$ hemichannels and the inhibition of pathological, excessive $\mathrm{Cx} 43$ hemichannel openings in disease conditions, including ischemia/reperfusion in the heart (Iyyathurai et al., 2013; Saez and Leybaert, 2014). Furthermore, these tools not only target plasmalemmal Cx43 hemichannels, but may also target $\mathrm{Cx} 43$ hemichannels present in the inner mitochondrial membrane (Boengler et al., 2013). For instance, $\mathrm{Cx} 43$ has been found in the inner mitochondrial membrane of subsarcolemmal mitochondria from ventricular cardiomyocytes (Boengler et al., 2009). Cx43 has been implicated in mitochondrial $\mathrm{K}^{+}$uptake (Miro-Casas et al., 2009). Genetic ablation of Cx43 as well as Gap19 decreased the rate of mitochondrial $\mathrm{K}^{+}$ uptake in subsarcolemmal mitochondria (Boengler et al., 2013). Hence, the acute inhibition of Cx43 hemichannels using Gap19 elucidated a novel cell biological role for $\mathrm{Cx} 43$ hemichannels at the level of the mitochondria modulating mitochondrial $\mathrm{K}^{+}$ uptake.

TAT-L2 has also been applied in the context of the brain. In particular, micro-injection of the TAT-L2 peptide in the basolateral amygdala, a region of the brain involved in memory consolidation, of auditory fear-conditioned rats resulted in ablation of memory consolidation without impacting short-term memory, locomotion, or shock reactivity or without affecting synaptic transmission or interastrocyte gap junctional communication (Stehberg et al., 2012). The amnesic effect of TAT-L2 was related to an impaired gliotransmitter release from astrocytes, since a cocktail of gliotransmitters including glutamate, glutamine, lactate, D-serine, glycine, and ATP could restore the learning capacity of the rats. As such, TAT-L2 as a selective Cx43-hemichannel inhibitor led to the discovery of a novel physiological role for $\mathrm{Cx} 43$ hemichannels as release pathways for gliotransmitters essential for memory consolidation in the basolateral amygdala.

TAT-CT10 has been applied in the context of satellite glial cells, the main glia in sensory ganglia. They are proposed to prevent the formation of electrical and chemical synapses between neighboring neurons. However, paracrine signaling between glial cells and sensory neurons may occur. A role for hemichannels has been implicated in increased vagal nerve activity after nodose neuron exposure to $\mathrm{Ca}^{2+}$-free solution. Interestingly, TAT-CT10 displayed a similar effect as $\mathrm{Ca}^{2+}$-free solution on these sensory neurons, thereby facilitating paracrine signaling between satellite glial cells and neurons (Retamal et al., 2014).

Gap19 has been applied in the context of the heart exposed to ischemia/reperfusion (Wang et al., 2013b). Importantly, Gap19 not only inhibited the "physiological" opening of native $\mathrm{Cx} 43$ hemichannels present in ventricular cardiomyocytes obtained from healthy hearts, but also suppressed the excessive, "pathophysiological" opening of Cx43 hemichannels from ventricular cardiomyocytes exposed to metabolic inhibition triggered by a mitochondrial uncoupler and a glycolysis inhibitor (Wang et al., 2013b). Consistent with this, Gap19 also suppressed the deleterious effects of ischemia/reperfusion on cardiomyocyte viability in vitro, thereby maintaining the cell volume of cardiomyocytes and limiting the occurrence of cell death. Finally, in vivo ischemia/reperfusion experiments in mice showed that pre-incubation with Gap19 significantly decreased the infarct size.

\section{REMAINING QUESTIONS AND FUTURE DIRECTIONS THE LINK BETWEEN THE ACTIN/MYOSIN CYTOSKELETON AND CX43 HEMICHANNELS?}

Two models for the regulation of $\mathrm{Cx} 43$ hemichannels by actin/myosin contractility, including a "direct" linker protein that bridges the C-terminal tail of $\mathrm{Cx} 43$ with the actin/myosin cytoskeleton and an "indirect" membrane-embedded "sensor" of the contractile state of the actin/myosin cytoskeleton that can also bind to the C-terminal tail of $\mathrm{Cx} 43$ hemichannels via an adaptor protein (Ponsaerts et al., 2012b). Different proteins associated with the actin/myosin cytoskeleton have been implicated in interactions with $\mathrm{Cx} 43$ proteins, but also actin may directly bind Cx43 proteins (Butkevich et al., 2004; Li et al., 2005; Wall et al., 2007; Sin et al., 2009; Vitale et al., 2009; Herve et al., 2012). In addition, we may not exclude that these interactions could be modulated by $\mathrm{Ca}^{2+}$-dependent changes in the phosphorylation state of $\mathrm{Cx} 43$ hemichannels due to the activation of $\mathrm{Ca}^{2+}$-dependent kinases or phosphatases (Solan and Lampe, 2009; O' quinn et al., 2011; Palatinus et al., 2011; Marquez-Rosado et al., 2012).

\section{OTHER DOMAINS WITHIN THE C-TERMINAL TAIL CONTRIBUTING TO THE CONTROL OF CX43-HEMICHANNEL ACTIVITY?}

The current model for loop/tail interactions controlling Cx43hemichannel activity involves the Gap19 region in the cytosplasmic loop and the CT10 region in the C-terminal tail. Although these domains are sufficient to either inhibit Cx43-hemichannel opening or to restore $\mathrm{Cx} 43$-hemichannel activity, it cannot be excluded that other domains in the C-terminal tail of $\mathrm{Cx} 43$ can modulate or contribute to the interactions with the Gap19/L2 region of the cytoplasmic loop and thus the activity of Cx43 hemichannels. In particular, previous studies in $\mathrm{Cx} 43$ gap junctions have implicated other domains acting as the gating particle controlling $\mathrm{Cx} 43$ gap junction activity. For instance, a 17-mer peptide corresponding to the region 271 to 287 of $\mathrm{Cx} 43$ is able to inhibit Cx43 gap junctions (Calero et al., 1998). However, the relevance of this region and/or other regions within the Cterminal tail for controlling $\mathrm{Cx} 43$-hemichannel activity remains to be elucidated.

\section{LOOP/TAIL INTERACTIONS AS A GENERAL CONCEPT IN CONTROLLING THE ACTIVITY OF OTHER CX ISOFORMS?}

It also remains to be elucidated whether the concept of loop/tail interactions being critical for the activity of $\mathrm{Cx}$ hemichannels is 
limited to $\mathrm{Cx} 43$ or can be a general mechanism operative in other $\mathrm{Cx}$ isoforms. In any case, although the "hot spots" for loop/tail interactions in Cx43 seem not highly conserved among other $\mathrm{Cx}$ isoforms (see Iyyathurai et al., 2013 for a detailed discussion), it could be possible that other amino acid stretches or motifs within the loop and tail of other $\mathrm{Cx}$ isoforms may establish such interactions. For instance, a recent report from Jiang and coworkers indicates that loop/tail interactions may exist in $\mathrm{Cx} 46$ hemichannels (Ren et al., 2013). Indeed, the $\mathrm{Cx} 46^{\mathrm{G} 143 \mathrm{R}}$ mutation decreases gap junctional coupling while increasing hemichannel activity. Consistent with this, a GST-fusion protein containing the Cx46 loop region displayed enhanced Cx46-binding properties when containing the cataract-causing G143R mutation (Ren et al., 2013). These data seem to suggest that at least for $\mathrm{Cx}$ isoforms belonging to the gap junction family, loop/tail interaction may be operative and control the opening of hemichannels. Interestingly, the introduction of an additional positive charge in the loop enhancing Cx46-hemichannel activity and promoting Cx46 binding seems to suggest a prominent role for charge-based interactions, similar to Cx43. Until now, there is no evidence whether other $\mathrm{Cx}$ isoforms belonging to other gap junction families can be controlled by loop/tail interactions. Of note, $\mathrm{Cx} 32$ also displays a bell-shaped dependence toward cytosolic $\left[\mathrm{Ca}^{2+}\right]$ rises (De Vuyst et al., 2006), but it remains to be established whether this is due to the occurrence of loop/tail interactions and their modulation by contractility.

\section{CONCLUSIONS}

We hereby show that primary BCECs are a good model system for studying the properties of native $\mathrm{Cx} 43$ hemichannels and their regulation by physiological signaling events. These studies ought to be complemented with knockdown experiments and ectopically expressed $\mathrm{Cx} 43$ hemichannels, allowing the expression of mutated and truncated $\mathrm{Cx} 43$ versions. The integrated approach has led to important discoveries, including the negative regulation of $\mathrm{Cx} 43$-hemichannel opening by the actin/myosin contractile system, the essential role of loop/tail interactions for Cx43-hemichannel activity and to the development of novel peptide tools that allow selective $\mathrm{Cx} 43$-hemichannel inhibition without affecting $\mathrm{Cx} 43$ gap junctions or hemichannels formed by other Cx isoforms.

\section{ACKNOWLEDGMENTS}

The authors are very grateful to all previous laboratory members and collaborators involved in the work and discussions. Research in the authors' laboratory has been supported by a research grant of the FWO (G.0298.11 to LL and GB) and a "Krediet aan Navorser" grant of the FWO (15117.14N to CDH).

\section{REFERENCES}

Armitage, W. J., Dick, A. D., and Bourne, W. M. (2003). Predicting endothelial cell loss and long-term corneal graft survival. Invest. Ophthalmol. Vis. Sci. 44, 3326-3331. doi: 10.1167/iovs.02-1255

Bergmann, L., Hartmann, C., Renard, G., Saragoussi, J. J., and Pouliquen, Y. (1991). [Damage to the corneal endothelium caused by radial keratotomy]. Fortschr. Ophthalmol. 88, 368-373.

Beuerman, R. W., and Pedroza, L. (1996). Ultrastructure of the human cornea. Microsc. Res. Tech. 33, 320-335.
Boengler, K., Stahlhofen, S., Van De Sand, A., Gres, P., Ruiz-Meana, M., GarciaDorado, D., et al. (2009). Presence of connexin 43 in subsarcolemmal, but not in interfibrillar cardiomyocyte mitochondria. Basic Res. Cardiol. 104, 141-147. doi: 10.1007/s00395-009-0007-5

Boengler, K., Ungefug, E., Heusch, G., Leybaert, L., and Schulz, R. (2013). Connexin 43 impacts on mitochondrial potassium uptake. Front. Pharmacol. 4:73. doi: $10.3389 /$ fphar.2013.00073

Bogatcheva, N. V., Garcia, J. G. N., and Verin, A. D. (2002). Molecular mechanisms of thrombin-induced endothelial cell permeability. Biochemistry Mosc. 67, 75-84. doi: 10.1023/A:1013904231324

Bonanno, J. A. (2003). Identity and regulation of ion transport mechanisms in the corneal endothelium. Prog. Retin. Eye Res. 22, 69-94. doi: 10.1016/S13509462(02)00059-9

Bonanno, J. A., and Giasson, C. (1992a). Intracellular pH regulation in fresh and cultured bovine corneal endothelium. I. Na ${ }^{+} / \mathrm{H}^{+}$exchange in the absence and presence of HCO3. Invest. Ophthalmol. Vis. Sci. 33, 3058-3067.

Bonanno, J. A., and Giasson, C. (1992b). Intracellular $\mathrm{pH}$ regulation in fresh and cultured bovine corneal endothelium. II. $\mathrm{Na}^{+}: \mathrm{HCO}_{3}^{-}$cotransport and $\mathrm{Cl}^{-} / \mathrm{HCO}_{3}^{-}$exchange. Invest. Ophthalmol. Vis. Sci. 33, 3068-3079.

Bourne, R. R., Minassian, D. C., Dart, J. K., Rosen, P., Kaushal, S., and Wingate, N. (2004). Effect of cataract surgery on the corneal endothelium: modern phacoemulsification compared with extracapsular cataract surgery. Ophthalmology 111, 679-685. doi: 10.1016/j.ophtha.2003.07.015

Bourne, W. M. (2001). Cellular changes in transplanted human corneas. Cornea 20, 560-569. doi: 10.1097/00003226-200108000-00002

Bourne, W. M. (2003). Biology of the corneal endothelium in health and disease. Eye 17, 912-918. doi: 10.1038/sj.eye.6700559

Bourne, W. M., and Brubaker, R. F. (1982). Decreased endothelial permeability in the iridocorneal endothelial syndrome. Ophthalmology 89, 591-595. doi: 10.1016/S0161-6420(82)34745-4

Bourne, W. M., and Brubaker, R. F. (1983). Decreased endothelial permeability in transplanted corneas. Am. J. Ophthalmol. 96, 362-367.

Bourne, W. M., and McLaren, J. W. (2004). Clinical responses of the corneal endothelium. Exp. Eye Res. 78, 561-572. doi: 10.1016/j.exer.2003.08.002

Bourne, W. M., Nelson, L. R., and Hodge, D. O. (1997). Central corneal endothelial cell changes over a ten-year period. Invest. Ophthalmol. Vis. Sci. 38, 779-782.

Brooks, A. M., and Gillies, W. E. (1991). Effect of angle closure glaucoma and surgical intervention on the corneal endothelium. Cornea 10, 489-497. doi: 10.1097/00003226-199111000-00005

Burridge, K., and Chrzanowska-Wodnicka, M. (1996). Focal adhesions, contractility, and signaling. Annu. Rev. Cell Dev. Biol. 12, 463-518. doi: 10.1146/annurev.cellbio.12.1.463

Butkevich, E., Hülsmann, S., Wenzel, D., Shirao, T., Duden, R., and Majoul, I. (2004). Drebrin is a novel connexin-43 binding partner that links gap junctions to the submembrane cytoskeleton. Curr. Biol. 14, 650-658. doi: 10.1016/j.cub.2004.03.063

Calero, G., Kanemitsu, M., Taffet, S. M., Lau, A. F., and Delmar, M. (1998). A 17mer peptide interferes with acidification-induced uncoupling of connexin43. Circ. Res. 82, 929-935. doi: 10.1161/01.RES.82.9.929

Chi, Y., Gao, K., Zhang, H., Takeda, M., and Yao, J. (2014). Suppression of cell membrane permeability by suramin: involvement of its inhibitory actions on connexin 43 hemichannels. Br. J. Pharmacol. 171, 3448-3462. doi: 10.1111/bph. 12693

Cotrina, M. L., Lin, J. H., and Nedergaard, M. (1998). Cytoskeletal assembly and ATP release regulate astrocytic calcium signaling. J. Neurosci. 18, 8794-8804.

Davson, H. (1949). Some considerations on the salt content of fresh and old ox cornea. Br. J. Ophthalmol. 33, 175-182. doi: 10.1136/bjo.33.3.175

De Bock, M., Culot, M., Wang, N., Da Costa, A., Decrock, E., Bol, M., et al. (2012a). Low extracellular $\mathrm{Ca} 2+$ conditions induce an increase in brain endothelial permeability that involves intercellular Ca2+ waves. Brain Res. 1487, 78-87. doi: 10.1016/j.brainres.2012.06.046

De Bock, M., Wang, N., Bol, M., Decrock, E., Ponsaerts, R., Bultynck, G., et al. (2012b). Connexin 43 hemichannels contribute to cytoplasmic $\mathrm{Ca}^{2+}$ oscillations by providing a bimodal $\mathrm{Ca}^{2+}$-dependent $\mathrm{Ca}^{2+}$ entry pathway. J. Biol. Chem. 287, 12250-12266. doi: 10.1074/jbc.M111.299610

De Bock, M., Wang, N., Decrock, E., Bol, M., Gadicherla, A. K., Culot, M., et al. (2013). Endothelial calcium dynamics, connexin channels and blood-brain barrier function. Prog. Neurobiol. 108, 1-20. doi: 10.1016/j.pneurobio.2013. 06.001 
Delmar, M., Coombs, W., Sorgen, P., Duffy, H. S., and Taffet, S. M. (2004). Structural bases for the chemical regulation of Connexin43 channels. Cardiovasc. Res. 62, 268-275. doi: 10.1016/j.cardiores.2003.12.030

Desplantez, T., Verma, V., Leybaert, L., Evans, W. H., and Weingart, R. (2012). Gap26, a connexin mimetic peptide, inhibits currents carried by connexin 43 hemichannels and gap junction channels. Pharmacol. Res. 65, 546-552. doi: 10.1016/j.phrs.2012.02.002

De Vuyst, E., Decrock, E., Cabooter, L., Dubyak, G. R., Naus, C. C., Evans, W. H., et al. (2006). Intracellular calcium changes trigger connexin 32 hemichannel opening. EMBO J. 25, 34-44. doi: 10.1038/sj.emboj.7600908

De Vuyst, E., Wang, N., Decrock, E., De Bock, M., Vinken, M., Van Moorhem, M., et al. (2009). $\mathrm{Ca}^{2+}$ regulation of connexin 43 hemichannels in C6 glioma and glial cells. Cell Calcium 46, 176-187. doi: 10.1016/j.ceca.2009.07.002

D'hondt, C., Himpens, B., and Bultynck, G. (2013a). Mechanical stimulationinduced calcium wave propagation in cell monolayers: the example of bovine corneal endothelial cells. J. Vis. Exp. 77:e50443. doi: 10.3791/50443

D’hondt, C., Iyyathurai, J., Wang, N., Gourdie, R. G., Himpens, B., Leybaert, L., et al. (2013b). Negatively charged residues (Asp378 and Asp379) in the last ten amino acids of the C-terminal tail of $\mathrm{Cx} 43$ hemichannels are essential for loop/tail interactions. Biochem. Biophys. Res. Commun. 432, 707-712. doi: 10.1016/j.bbrc.2013.01.066

D’hondt, C., Ponsaerts, R., Srinivas, S. P., Vereecke, J., and Himpens, B. (2007a). Thrombin inhibits intercellular calcium wave propagation in corneal endothelial cells by modulation of hemichannels and gap junctions. Invest. Ophthalmol. Vis. Sci. 48, 120-133. doi: 10.1167/iovs.06-0770

D’hondt, C., Ponsaerts, R., Srinivas, S. P., Vereecke, J., and Himpens, B. (2009). Reduced intercellular communication and altered morphology of bovine corneal endothelial cells with prolonged time in cell culture. Curr. Eye Res. 34, 454-465. doi: 10.1080/02713680902913022

D'hondt, C., Srinivas, S. P., Vereecke, J., and Himpens, B. (2007b). Adenosine opposes thrombin-induced inhibition of intercellular calcium wave in corneal endothelial cells. Invest. Ophthalmol. Vis. Sci. 48, 1518-1527. doi: 10.1167/iovs.06-1062

Dikstein, S., and Maurice, D. M. (1972). The active control of corneal hydration. Isr. J. Med. Sci. 8, 1523-1528.

Dudek, S. M., and Garcia, J. G. (2001). Cytoskeletal regulation of pulmonary vascular permeability. J. Appl. Physiol. 91, 1487-1500.

Duffy, H. S., Sorgen, P. L., Girvin, M. E., O'donnell, P., Coombs, W., Taffet, S. M., et al. (2002). pH-dependent intramolecular binding and structure involving Cx43 cytoplasmic domains. J. Biol. Chem. 277, 36706-36714. doi: 10.1074/jbc.M207016200

Edelhauser, H. F. (2000). The resiliency of the corneal endothelium to refractive and intraocular surgery. Cornea 19, 263-273. doi: 10.1097/00003226-20000500000002

Evans, W. H., Bultynck, G., and Leybaert, L. (2012). Manipulating connexin communication channels: use of peptidomimetics and the translational outputs. J. Membr. Biol. 245, 437-449. doi: 10.1007/s00232-012-9488-5

Gagnon, M. M., Boisjoly, H. M., Brunette, I., Charest, M., and Amyot, M. (1997). Corneal endothelial cell density in glaucoma. Cornea 16, 314-318. doi: 10.1097/00003226-199705000-00010

Garcia, J. G., Davis, H. W., and Patterson, C. E. (1995). Regulation of endothelial cell gap formation and barrier dysfunction: role of myosin light chain phosphorylation. J. Cell. Physiol. 163, 510-522. doi: 10.1002/jcp.1041630311

Garcia, J. G., Lazar, V., Gilbert-McClain, L. I., Gallagher, P. J., and Verin, A. D. (1997). Myosin light chain kinase in endothelium: molecular cloning and regulation. Am. J. Respir. Cell Mol. Biol. 16, 489-494. doi: 10.1165/ajrcmb.16.5.9160829

Garcia, J. G., and Schaphorst, K. L. (1995). Regulation of endothelial cell gap formation and paracellular permeability. J. Investig. Med. 43, 117-126.

Garcia, J. G., Verin, A. D., and Schaphorst, K. L. (1996). Regulation of thrombinmediated endothelial cell contraction and permeability. Semin. Thromb. Hemost. 22, 309-315. doi: 10.1055/s-2007-999025

George, A. J. T., and Larkin, D. F. P. (2004). Corneal transplantation: the forgotten graft. Am. J. Transplant 4, 678-685. doi: 10.1111/j.1600-6143.2004.00417.x

Giepmans, B. N., and Moolenaar, W. H. (1998). The gap junction protein connexin43 interacts with the second PDZ domain of the zona occludens-1 protein. Curr. Biol. 8, 931-934. doi: 10.1016/S0960-9822(07)00375-2

Gomes, P., Srinivas, S. P., Van Driessche, W., Vereecke, J., and Himpens, B. (2005a). ATP release through connexin hemichannels in corneal endothelial cells. Invest. Ophthalmol. Vis. Sci. 46, 1208-1218. doi: 10.1167/iovs. 04-1181

Gomes, P., Srinivas, S. P., Vereecke, J., and Himpens, B. (2005b). ATP-dependent paracrine intercellular communication in cultured bovine corneal endothelial cells. Invest. Ophthalmol. Vis. Sci. 46, 104-113. doi: 10.1167/iovs.04-0846

Gomes, P., Srinivas, S. P., Vereecke, J., and Himpens, B. (2006). Gap junctional intercellular communication in bovine corneal endothelial cells. Exp. Eye Res. 83, 1225-1237. doi: 10.1016/j.exer.2006.06.012

Grupcheva, C. N., Laux, W. T., Rupenthal, I. D., McGhee, J., McGhee, C. N., and Green, C. R. (2012). Improved corneal wound healing through modulation of gap junction communication using connexin43-specific antisense oligodeoxynucleotides. Invest. Ophthalmol. Vis. Sci. 53, 1130-1138. doi: 10.1167/iovs.11-8711

Guinamard, R., Simard, C., and Del Negro, C. (2013). Flufenamic acid as an ion channel modulator. Pharmacol. Ther. 138, 272-284. doi: 10.1016/j.pharmthera.2013.01.012

Hajnoczky, G., Robb-Gaspers, L. D., Seitz, M. B., and Thomas, A. P. (1995). Decoding of cytosolic calcium oscillations in the mitochondria. Cell 82, 415-424. doi: 10.1016/0092-8674(95)90430-1

Herve, J. C., Derangeon, M., Sarrouilhe, D., Giepmans, B. N., and Bourmeyster, N. (2012). Gap junctional channels are parts of multiprotein complexes. Biochim. Biophys. Acta 1818, 1844-1865. doi: 10.1016/j.bbamem.2011.12.009

Hirst-Jensen, B. J., Sahoo, P., Kieken, F., Delmar, M., and Sorgen, P. L. (2007). Characterization of the $\mathrm{pH}$-dependent interaction between the gap junction protein connexin43 carboxyl terminus and cytoplasmic loop domains. J. Biol. Chem. 282, 5801-5813. doi: 10.1074/jbc.M605233200

Hoppenreijs, V. P., Pels, E., Vrensen, G. F., Oosting, J., and Treffers, W. F. (1992). Effects of human epidermal growth factor on endothelial wound healing of human corneas. Invest. Ophthalmol. Vis. Sci. 33, 1946-1957.

Hull, D. S., Green, K., Boyd, M., and Wynn, H. R. (1977). Corneal endothelium bicarbonate transport and the effect of carbonic anhydrase inhibitors on endothelial permeability and fluxes and corneal thickness. Invest. Ophthalmol. Vis. Sci. 16, 883-892.

Hunter, A. W., Barker, R. J., Zhu, C., and Gourdie, R. G. (2005). Zonula occludens1 alters connexin43 gap junction size and organization by influencing channel accretion. Mol. Biol. Cell 16, 5686-5698. doi: 10.1091/mbc.E05-08-0737

Ichijima, H., Petroll, W. M., Barry, P. A., Andrews, P. M., Dai, M., Cavanagh, H. D., et al. (1993a). Actin filament organization during endothelial wound healing in the rabbit cornea: comparison between transcorneal freeze and mechanical scrape injuries. Invest. Ophthalmol. Vis. Sci. 34, 2803-2812.

Ichijima, H., Petroll, W. M., Jester, J. V., Barry, P. A., Andrews, P. M., Dai, M., et al. (1993b). In vivo confocal microscopic studies of endothelial wound healing in rabbit cornea. Cornea 12, 369-378. doi: 10.1097/00003226-199309000-00001

Iyyathurai, J., D’hondt, C., Wang, N., De Bock, M., Himpens, B., Retamal, M. A., et al. (2013). Peptides and peptide-derived molecules targeting the intracellular domains of Cx43: gap junctions versus hemichannels. Neuropharmacology 75, 491-505. doi: 10.1016/j.neuropharm.2013.04.050

Joyce, N. C. (2003). Proliferative capacity of the corneal endothelium. Prog. Retin. Eye Res. 22, 359-389. doi: 10.1016/S1350-9462(02)00065-4

Joyce, N. C., Matkin, E. D., and Neufeld, A. H. (1989). Corneal endothelial wound closure in vitro. Effects of EGF and/or indomethacin. Invest. Ophthalmol. Vis. Sci. 30, 1548-1559.

Joyce, N. C., and Meklir, B. (1994). PGE2: a mediator of corneal endothelial wound repair in vitro. Am. J. Physiol. 266, C269-C275.

Kamm, K. E., and Stull, J. T. (2001). Dedicated myosin light chain kinases with diverse cellular functions. J. Biol. Chem. 276, 4527-4530. doi: 10.1074/jbc.R000028200

Koh, S. W. (2012). Corneal endothelial autocrine trophic factor VIP in a mechanism-based strategy to enhance human donor cornea preservation for transplantation. Exp. Eye Res. 95, 48-53. doi: 10.1016/j.exer.2011.10.005

Koh, S. W., Gloria, D., and Molloy, J. (2011). Corneal endothelial autocrine VIP enhances its integrity in stored human donor corneoscleral explant. Invest. Ophthalmol. Vis. Sci. 52, 5632-5640. doi: 10.1167/iovs.10-5983

Laing, R. A., Sanstrom, M. M., Berrospi, A. R., and Leibowitz, H. M. (1976). Changes in the corneal endothelium as a function of age. Exp. Eye Res. 22, 587-594. doi: 10.1016/0014-4835(76)90003-8

Landshman, N., Ben-Hanan, I., Assia, E., Ben-Chaim, O., and Belkin, M. (1988). Relationship between morphology and functional ability of regenerated corneal endothelium. Invest. Ophthalmol. Vis. Sci. 29, 1100-1109. 
Laux-Fenton, W. T., Donaldson, P. J., Kistler, J., and Green, C. R. (2003). Connexin expression patterns in the rat cornea: molecular evidence for communication compartments. Cornea 22, 457-464. doi: 10.1097/00003226-20030700000012

Leybaert, L., and Sanderson, M. J. (2012). Intercellular $\mathrm{Ca}^{2+}$ waves: mechanisms and function. Physiol. Rev. 92, 1359-1392. doi: 10.1152/physrev.00029.2011

Li, W., Hertzberg, E. L., and Spray, D. C. (2005). Regulation of connexin43-protein binding in astrocytes in response to chemical ischemia/hypoxia. J. Biol. Chem. 280, 7941-7948. doi: 10.1074/jbc.M410548200

Lucas-Lopez, C., Allingham, J. S., Lebl, T., Lawson, C. P., Brenk, R., Sellers, J. R., et al. (2008). The small molecule tool (S)-(-)-blebbistatin: novel insights of relevance to myosin inhibitor design. Org. Biomol. Chem. 6, 2076-2084. doi: $10.1039 / \mathrm{b} 801223 \mathrm{~g}$

Marquez-Rosado, L., Solan, J. L., Dunn, C. A., Norris, R. P., and Lampe, P. D. (2012). Connexin43 phosphorylation in brain, cardiac, endothelial and epithelial tissues. Biochim. Biophys. Acta 1818, 1985-1992. doi: 10.1016/j.bbamem.2011.07.028

Matsubara, M., and Tanishima, T. (1983). Wound-healing of corneal endothelium in monkey: an autoradiographic study. Jpn. J. Ophthalmol. 27, 444-450.

Maurice, D. M. (1957). The structure and transparency of the cornea. J. Physiol. (Lond.) 136, 263-286.

Maurice, D. M. (1972). The location of the fluid pump in the cornea. J. Physiol. (Lond.) 221, 43-54.

Mehta, D., and Malik, A. B. (2006). Signaling mechanisms regulating endothelial permeability. Physiol. Rev. 86, 279-367. doi: 10.1152/physrev.00012.2005

Mimura, T., and Joyce, N. C. (2006). Replication competence and senescence in central and peripheral human corneal endothelium. Invest. Ophthalmol. Vis. Sci. 47, 1387-1396. doi: 10.1167/iovs.05-1199

Miro-Casas, E., Ruiz-Meana, M., Agullo, E., Stahlhofen, S., Rodriguez-Sinovas, A., Cabestrero, A., et al. (2009). Connexin43 in cardiomyocyte mitochondria contributes to mitochondrial potassium uptake. Cardiovasc. Res. 83, 747-756. doi: $10.1093 / \mathrm{cvr} / \mathrm{cvp} 157$

Moller-Pedersen, T. (1997). A comparative study of human corneal keratocyte and endothelial cell density during aging. Cornea 16, 333-338.

Moreno, A. P., Chanson, M., Elenes, S., Anumonwo, J., Scerri, I., Gu, H., et al. (2002). Role of the carboxyl terminal of connexin43 in transjunctional fast voltage gating. Circ. Res. 90, 450-457. doi: 10.1161/hh0402.105667

Murphy, C., Alvarado, J., Juster, R., and Maglio, M. (1984). Prenatal and postnatal cellularity of the human corneal endothelium. A quantitative histologic study. Invest. Ophthalmol. Vis. Sci. 25, 312-322.

Nakano, Y., Oyamada, M., Dai, P., Nakagami, T., Kinoshita, S., and Takamatsu, T. (2008). Connexin43 knockdown accelerates wound healing but inhibits mesenchymal transition after corneal endothelial injury in vivo. Invest. Ophthalmol. Vis. Sci. 49, 93-104. doi: 10.1167/iovs.07-0255

O'quinn, M. P., Palatinus, J. A., Harris, B. S., Hewett, K. W., and Gourdie, R. G. (2011). A peptide mimetic of the connexin43 carboxyl terminus reduces gap junction remodeling and induced arrhythmia following ventricular injury. Circ. Res. 108, 704-715. doi: 10.1161/CIRCRESAHA.110.235747

Palatinus, J. A., Rhett, J. M., and Gourdie, R. G. (2011). Enhanced PKCepsilon mediated phosphorylation of connexin 43 at serine 368 by a carboxyl-terminal mimetic peptide is dependent on injury. Channels (Austin). 5, 236-240. doi: 10.4161/chan.5.3.15834

Ponsaerts, R., D’hondt, C., Gomes, P., Bultynck, G., Srinivas, S. P., Vereecke, J., et al. (2010a). "ATP release via connexin hemichannels controls intercellular propagation of Ca2+ waves in corneal endothelial cells," in Extracellular ATP and Adenosine as Regulators of Endothelial Cell Function, eds E. Gerasimovskaya and E. Kaczmarek (Berlin: Springer-Verlag), 161-195.

Ponsaerts, R., De Vuyst, E., Retamal, M., D’hondt, C., Vermeire, D., Wang, N., et al. (2010b). Intramolecular loop/tail interactions are essential for connexin 43-hemichannel activity. FASEB J. 24, 4378-4395. doi: 10.1096/fj.09-153007

Ponsaerts, R., D'hondt, C., Bultynck, G., Srinivas, S. P., Vereecke, J., and Himpens, B. (2008). The myosin II ATPase inhibitor blebbistatin prevents thrombin-induced inhibition of intercellular calcium wave propagation in corneal endothelial cells. Invest. Ophthalmol. Vis. Sci. 49, 4816-4827. doi: 10.1167/iovs.07-1533

Ponsaerts, R., D’hondt, C., Hertens, F., Parys, J. B., Leybaert, L., Vereecke, J., et al. (2012a). RhoA GTPase switch controls Cx43-hemichannel activity through the contractile system. PLoS ONE 7:e42074. doi: 10.1371/journal.pone.0042074
Ponsaerts, R., Wang, N., Himpens, B., Leybaert, L., and Bultynck, G. (2012b). The contractile system as a negative regulator of the connexin 43 hemichannel. Biol. Cell 104, 367-377. doi: 10.1111/boc.201100079

Rao, G. N., Waldron, W. R., and Aquavella, J. V. (1978). Fate of endothelium in a corneal graft. Ann. Ophthalmol. 10, 645-649.

Ren, Q., Riquelme, M. A., Xu, J., Yan, X., Nicholson, B. J., Gu, S., et al. (2013). Cataract-causing mutation of human connexin 46 impairs gap junction, but increases hemichannel function and cell death. PLOS ONE 8:e74732. doi: 10.1371/journal.pone.0074732

Retamal, M. A., Alcayaga, J., Bultynck, G., Sáez, P. J., Fernandez, R., León, L. E., et al. (2014). Opening of pannexin and connexin based-channels increases the excitability of nodose ganglion sensory neurons. Front. Cell. Neurosci. 8:158. doi: $10.3389 /$ fncel.2014.00158

Rhett, J. M., Jourdan, J., and Gourdie, R. G. (2011). Connexin 43 connexon to gap junction transition is regulated by zonula occludens-1. Mol. Biol. Cell 22, 1516-1528. doi: 10.1091/mbc.E10-06-0548

Riley, M. (1985). Pump and leak in regulation of fluid transport in rabbit cornea. Curr. Eye Res. 4, 371-376. doi: 10.3109/02713688509025150

Riley, M. V., Winkler, B. S., Starnes, C. A., and Peters, M. I. (1996). Adenosine promotes regulation of corneal hydration through cyclic adenosine monophosphate. Invest. Ophthalmol. Vis. Sci. 37, 1-10.

Riley, M. V., Winkler, B. S., Starnes, C. A., Peters, M. I., and Dang, L. (1998). Regulation of corneal endothelial barrier function by adenosine, cyclic AMP, and protein kinases. Invest. Ophthalmol. Vis. Sci. 39, 2076-2084.

Saez, J. C., and Leybaert, L. (2014). Hunting for connexin hemichannels. FEBS Lett. 588, 1205-1211. doi: 10.1016/j.febslet.2014.03.004

Satpathy, M., Gallagher, P., Jin, Y., and Srinivas, S. P. (2005). Extracellular ATP opposes thrombin-induced myosin light chain phosphorylation and loss of barrier integrity in corneal endothelial cells. Exp. Eye Res. 81, 183-192. doi: 10.1016/j.exer.2005.01.026

Satpathy, M., Gallagher, P., Waniewski, M. L., and Srinivas, S. P. (2004). Thrombininduced phosphorylation of the regulatory light chain of myosin II in cultured bovine corneal endothelial cells. Exp. Eye Res. 79, 477-486. doi: 10.1016/j.exer.2004.06.018

Schultz, R. O., Matsuda, M., Yee, R. W., Edelhauser, H. F., and Schultz, K. J. (1984). Corneal endothelial changes in type I and type II diabetes mellitus. Am. J. Ophthalmol. 98, 401-410. doi: 10.1016/0002-9394(84)90120-X

Seki, A., Duffy, H. S., Coombs, W., Spray, D. C., Taffet, S. M., and Delmar, M. (2004). Modifications in the biophysical properties of connexin43 channels by a peptide of the cytoplasmic loop region. Circ. Res. 95, e22-e28. doi: 10.1161/01.RES.0000140737.62245.c5

Sin, W. C., Tse, M., Planque, N., Perbal, B., Lampe, P. D., and Naus, C. C. (2009). Matricellular protein CCN3 (NOV) regulates actin cytoskeleton reorganization. J. Biol. Chem. 284, 29935-29944. doi: 10.1074/jbc.M109.042630

Solan, J. L., and Lampe, P. D. (2009). Connexin43 phosphorylation: structural changes and biological effects. Biochem. J. 419, 261-272. doi: 10.1042/BJ20082319

Somlyo, A. P., and Somlyo, A. V. (2000). Signal transduction by G-proteins, rhokinase and protein phosphatase to smooth muscle and non-muscle myosin II. J. Physiol. (Lond.) 2, 177-185. doi: 10.1111/j.1469-7793.2000.t01-2-00177.x

Srinivas, S. P., Satpathy, M., Gallagher, P., Larivière, E., and Van Driessche, W. (2004). Adenosine induces dephosphorylation of myosin II regulatory light chain in cultured bovine corneal endothelial cells. Exp. Eye Res. 79, 543-551. doi: 10.1016/j.exer.2004.06.027

Srinivas, S. P., Yeh, J. C., Ong, A., and Bonanno, J. A. (1998). Ca2+ mobilization in bovine corneal endothelial cells by $\mathrm{P} 2$ purinergic receptors. Curr. Eye Res. 17, 994-1004. doi: 10.1076/ceyr.17.10.994.5242

Stehberg, J., Moraga-Amaro, R., Salazar, C., Becerra, A., Echeverria, C., Orellana, J. A., et al. (2012). Release of gliotransmitters through astroglial connexin 43 hemichannels is necessary for fear memory consolidation in the basolateral amygdala. FASEB J. 26, 3649-3657. doi: 10.1096/fj.11-198416

Stevenson, B. R. (1999). Understanding tight junction clinical physiology at the molecular level. J. Clin. Invest. 104, 3-4. doi: 10.1172/JCI7599

Straight, A. F., Cheung, A., Limouze, J., Chen, I., Westwood, N. J., Sellers, J. R., et al. (2003). Dissecting temporal and spatial control of cytokinesis with a myosin II Inhibitor. Science 299, 1743-1747. doi: 10.1126/science.1081412

Tandon, P. N., and Autar, R. (1989). Flow of aqueous humor in the canal of Schlemm. Math. Biosci. 93, 53-78. doi: 10.1016/0025-5564(89)90013-8 
Tsukamoto, A., Hayashida, Y., Furukawa, K. S., and Ushida, T. (2010). Spatiotemporal PLC activation in parallel with intracellular Ca2+ wave propagation in mechanically stimulated single MDCK cells. Cell Calcium 47, 253-263. doi: 10.1016/j.ceca.2009.12.008

Tuft, S. J., and Coster, D. J. (1990). The corneal endothelium. Eye 4 (Pt 3), 389-424. doi: 10.1038/eye.1990.53

Turner, J. R. (2000). "Putting the squeeze" on the tight junction: understanding cytoskeletal regulation. Semin. Cell Dev. Biol. 11, 301-308. doi: $10.1006 /$ scdb. 2000.0180

Turner, J. R., Rill, B. K., Carlson, S. L., Carnes, D., Kerner, R., Mrsny, R. J., et al. (1997). Physiological regulation of epithelial tight junctions is associated with myosin light-chain phosphorylation. Am. J. Physiol. 273, C1378-C1385.

Van Nieuw Amerongen, G. P., Vermeer, M. A., and Van Hinsbergh, V. W. (2000) Role of RhoA and Rho kinase in lysophosphatidic acid-induced endothelial barrier dysfunction. Arterioscler. Thromb. Vasc. Biol. 20, E127-E133. doi: 10.1161/01.ATV.20.12.e127

Vitale, M. L., Akpovi, C. D., and Pelletier, R. M. (2009). Cortactin/tyrosinephosphorylated cortactin interaction with connexin 43 in mouse seminiferous tubules. Microsc. Res. Tech. 72, 856-867. doi: 10.1002/jemt.20771

Vouret-Craviari, V., Bourcier, C., Boulter, E., and Van Obberghen-Schilling, E. (2002). Distinct signals via Rho GTPases and Src drive shape changes by thrombin and sphingosine-1-phosphate in endothelial cells. J. Cell Sci. 115, 2475-2484.

Wall, M. E., Otey, C., Qi, J., and Banes, A. J. (2007). Connexin 43 is localized with actin in tenocytes. Cell Motil. Cytoskeleton 64, 121-130. doi: 10.1002/cm.20170

Wang, N., De Bock, M., Antoons, G., Gadicherla, A. K., Bol, M., Decrock, E., et al. (2012). Connexin mimetic peptides inhibit Cx43 hemichannel opening triggered by voltage and intracellular Ca2+ elevation. Basic Res. Cardiol. 107, 304. doi: 10.1007/s00395-012-0304-2

Wang, N., De Bock, M., Decrock, E., Bol, M., Gadicherla, A., Bultynck, G., et al. (2013a). Connexin targeting peptides as inhibitors of voltage- and intracellular Ca2+-triggered Cx43 hemichannel opening. Neuropharmacology 75, 506-516. doi: 10.1016/j.neuropharm.2013.08.021

Wang, N., De Bock, M., Decrock, E., Bol, M., Gadicherla, A., Vinken, M., et al. (2013c). Paracrine signaling through plasma membrane hemichannels. Biochim. Biophys. Acta 1828, 35-50. doi: 10.1016/j.bbamem.2012.07.002
Wang, N., De Vuyst, E., Ponsaerts, R., Boengler, K., Palacios-Prado, N., Wauman, J., et al. (2013b). Selective inhibition of Cx43 hemichannels by Gap19 and its impact on myocardial ischemia/reperfusion injury. Basic Res. Cardiol. 108, 309. doi: 10.1007/s00395-012-0309-x

Waring, G. O. 3rd., Bourne, W. M., Edelhauser, H. F., and Kenyon, K. R. (1982) The corneal endothelium. Normal and pathologic structure and function. Ophthalmology 89, 531-590. doi: 10.1016/S0161-6420(82)34746-6

Williams, K., and Watsky, M. (2002). Gap junctional communication in the human corneal endothelium and epithelium. Curr. Eye Res. 25, 29-36. doi: 10.1076/ceyr.25.1.29.9964

Zhao, Y., and Davis, H. W. (1999). Signaling pathways in thrombin-induced actin reorganization in pulmonary artery endothelial cells. Exp. Lung Res. 25, 23-39. doi: $10.1080 / 019021499270402$

Zhu, C., and Joyce, N. C. (2004). Proliferative response of corneal endothelial cells from young and older donors. Invest. Ophthalmol. Vis. Sci. 45, 1743-1751. doi: 10.1167/iovs.03-0814

Conflict of Interest Statement: The authors declare that the research was conducted in the absence of any commercial or financial relationships that could be construed as a potential conflict of interest.

Received: 14 July 2014; paper pending published: 06 August 2014; accepted: 25 August 2014; published online: 12 September 2014.

Citation: D'hondt C, Iyyathurai J, Himpens B, Leybaert L and Bultynck G (2014)

Cx43-hemichannel function and regulation in physiology and pathophysiology: insights from the bovine corneal endothelial cell system and beyond. Front. Physiol. 5:348. doi: 10.3389/fphys.2014.00348

This article was submitted to Membrane Physiology and Membrane Biophysics, a section of the journal Frontiers in Physiology.

Copyright (c) 2014 D'hondt, Iyyathurai, Himpens, Leybaert and Bultynck. This is an open-access article distributed under the terms of the Creative Commons Attribution License (CC BY). The use, distribution or reproduction in other forums is permitted, provided the original author(s) or licensor are credited and that the original publication in this journal is cited, in accordance with accepted academic practice. No use, distribution or reproduction is permitted which does not comply with these terms. 